\title{
Novel amphiphilic pyridinium ionic liquids-supported Schiff bases: ultrasound assisted synthesis, molecular docking and anticancer evaluation
}

\author{
Fawzia Faleh Al-Blewi ${ }^{1}$, Nadjet Rezki ${ }^{1,2^{*}}$, Salsabeel Abdullah Al-Sodies ${ }^{1}$, Sanaa K. Bardaweel ${ }^{3}$, Dima A. Sabbah ${ }^{4}$, \\ Mouslim Messali ${ }^{1}$ and Mohamed Reda Aouad ${ }^{1 *}$
}

\begin{abstract}
Background: Pyridinium Schiff bases and ionic liquids have attracted increasing interest in medicinal chemistry. Results: A library of 32 cationic fluorinated pyridinium hydrazone-based amphiphiles tethering fluorinated counteranions was synthesized by alkylation of 4-fluoropyridine hydrazone with various long alkyl iodide exploiting lead quaternization and metathesis strategies. All compounds were assessed for their anticancer inhibition activity towards different cancer cell lines and the results revealed that increasing the length of the hydrophobic chain of the synthesized analogues appears to significantly enhance their anticancer activities. Substantial increase in caspase-3 activity was demonstrated upon treatment with the most potent compounds, namely $\mathbf{8}, \mathbf{2 8}, \mathbf{2 9}$ and $\mathbf{3 2}$ suggesting an apoptotic cellular death pathway.
\end{abstract}

Conclusions: Quantum-polarized ligand docking studies against phosphoinositide 3-kinase a displayed that compounds 2-6 bind to the kinase site and form H-bond with S774, K802, H917 and D933.

Keywords: Cationic, Amphiphilic, Pyridinium, Hydrazones, Ultrasound, Anticancer, QPLD docking

\section{Introduction}

Schiff bases have been widely investigated due to a broad spectrum of relevant properties in biological and pharmaceutical areas [1]. In addition, a number of molecules having azomethine Schiff base skeleton are the clinically approved drugs [2]. Meanwhile, carbohydrazide hydrazone and their derivatives an interesting class of Schiff bases, represented reliable and highly efficient pharmacophores in drug discovery and played a vital role in medical chemistry due to their potency to exhibit significant antimicrobial [3], anticancer [4, 5], anti-HIV [6], and anticandidal [7] activities. Azomethine hydrazone linkages $\left(R C O N H N=C R^{1} R^{2}\right)$ are one of the versatile and

\footnotetext{
*Correspondence: nadjetrezki@yahoo.fr; aouadmohamedreda@yahoo.fr

${ }^{1}$ Department of Chemistry, Faculty of Science, Taibah University,

Al-Madinah Al-Munawarah, Medina 30002, Saudi Arabia

Full list of author information is available at the end of the article
}

attractive functional groups in organic synthesis $[8,9]$. Their ability to react with electrophilic and nucleophilic reagents make them valuable candidates for the construction of diverse heterocyclic scaffolds [10]. Some pyridine hydrazones have been reported to possess fascinating chemotherapeutic properties $[11,12]$. On the other hand, biological and toxicity of pyridinium salts have been well documented due to their increasing applications. More specifically, pyridinium salts carrying long alkyl chains were found to be outstanding bioactive agents as antimicrobial [13], anticancer [14] and biodegradable [15] agents. Recently, we have reported a green ultrasound synthesis of novel fluorinated pyridinium hydrazones using a series of alkyl halides ranging from C2 to C7 [16]. The biological screening results revealed that the activity increased with increasing the length of the alkyl side chains, especially for hydrazones tethering fluorinated counteranions $\left(\mathrm{PF}_{6}^{-}, \mathrm{BF}_{4}^{-}\right.$and $\left.\mathrm{CF}_{3} \mathrm{COO}^{-}\right)$. 
Encouraged by these findings and in continuation of our efforts in designing highly active heterocyclic hydrazones [17-19], we aim to introduce a lipophilic long alkyl chain to a hydrazone skeleton to develop a new class of bioactive molecules. In the present work, a series of novel cationic fluorinated pyridinium hydrazone-based amphiphiles tethering different fluorinated counteranions were designed, synthesized and screened for their anticancer activities against four different cell lines. Additionally, their activities were further characterized via investigating the Caspase- 3 signaling pathway, a hallmark of apoptosis that is commonly studied to understand the mechanism of cellular death.

Molecular quantum-polarized ligand docking (QPLD) studies were carried out employing MAESTRO [20] software against the kinase domain of phosphoinositide 3-kinase $\alpha(\mathrm{PI} 3 \mathrm{~K} \alpha)$ [21] to identify their structural-basis of binding and ligand/receptor complex formation.

\section{Results and discussion} Synthesis

The methodology for affecting the sequence of reactions utilized ultrasound irradiations which have been widely used by our team as an alternative source of energy. Starting from fluorinated pyridine hydrazone 1, the quaternization of pyridine ring through its conventional alkylation with various long alkyl iodide with chain ranging from $\mathrm{C}_{8}$ to $\mathrm{C}_{18}$, in boiling acetonitrile as well as under ultrasound irradiation and gave the desired cationic fluorinated pyridinium hydrazones 2-9 tethering lipophilic side chain and iodide counteranion in good yields (Scheme 1). Short reactions time were required (10-12 h) when the ultrasound irradiations were used as an alternative energy source (Table 1).

The structure of newly designed pyridinium cationic surfactants 2-9 have been elucidated based on their spectral data (IR, NMR, Mass). Their IR spectra revealed the appearance of new characteristic bands at 2870$2969 \mathrm{~cm}^{-1}$ attributed to the aliphatic $\mathrm{C}-\mathrm{H}$ stretching which confirmed the presence of alkyl side chain in this structure. The ${ }^{1} \mathrm{H}$ NMR analysis showed one methyl and methylene groups resonating as two multiplets between $\delta_{\mathrm{H}} 0.74-0.87 \mathrm{ppm}$ and $1.16-1.32 \mathrm{ppm}$, respectively. The spectra also showed the presence of characteristic triplet and/or doublet of doublet ranging between $\delta_{\mathrm{H}} 4.68-$ 4.78 ppm assigned to $\mathrm{NCH}_{2}$ protons.

In addition, the imine proton $(\mathrm{H}-\mathrm{C}=\mathrm{N})$ resonated as two set of singlets at $\delta_{\mathrm{H}} 8.15-8.50 \mathrm{ppm}$ with a $1: 3$ ratio. The presence of such pairing of signals confirmed that these compounds exist as $E /$ cis and $E /$ trans diastereomers.

The ${ }^{13} \mathrm{C}$ NMR data also confirmed the appearance of $E /$ cis and $E /$ trans diastereomers through the presence of two peaks at $\delta_{\mathrm{H}} 58.60$ and $62.74 \mathrm{ppm}$ for $\mathrm{NCH}_{2}$. In the downfield region between $\delta_{\mathrm{C}} 156.38-165.76 \mathrm{ppm}$, the carbonyl and the imine carbons of the hydrazone linkage resonated as two sets of signals.

In their ${ }^{19} \mathrm{~F}$ NMR spectra, the aromatic fluorine atom appeared as two mutiplet signals between $\delta_{\mathrm{H}}(-107.98$ to $-109.89 \mathrm{ppm})$ and ( -107.72 to $-109.37 \mathrm{ppm})$.

Treatment of the halogenated pyridinium hydrazones 2-9 with fluorinated metal salts $\left(\mathrm{KPF}_{6}, \mathrm{NaBF}_{4}\right.$ or $\mathrm{NaOOCCF}_{3}$ ) afforded the targeted cationic amphiphilic fluorinated pyridinium hydrazones 10-33 carrying variant fluorinated counteranions (Scheme 2). The reaction involved the anion exchange and was carried out in short time $(6 \mathrm{~h})$ under ultrasound irradiation and gave comparative yields with those obtained using classical heating (16 h) (Table 2).

Structural differentiation between the metathetical products 10-33 and their halogenated precursors 2-9 was very difficult on the basis of their ${ }^{1} \mathrm{H}$ NMR and ${ }^{13} \mathrm{C}$ NMR spectra because they displayed virtually the same characteristic proton and carbon signals.

Consequently, other spectroscopic techniques $\left({ }^{19} \mathrm{~F},{ }^{31} \mathrm{P}\right.$,

${ }^{11} \mathrm{~B}$ NMR and mass spectroscopy) have been adopted to confirm the presence of fluorinated counteranions $\left(\mathrm{PF}_{6}{ }^{-}\right.$, $\mathrm{BF}_{4}^{-}$and $\mathrm{CF}_{3} \mathrm{COO}^{-}$) in the structure of the resulted ILs 10-33.

Thus, the presence of $\mathrm{PF}_{6}{ }^{-}$in ILs 10, 13, 16, 19, 22, 25, 28 and 31 has been established by their ${ }^{31} \mathrm{P}$ and ${ }^{19} \mathrm{~F}$ NMR analysis. Thus, the resonance of a diagnostic

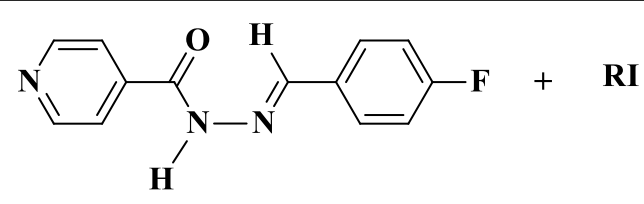

1

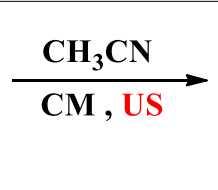

$\mathrm{R}=-\left(\mathrm{CH}_{2}\right)_{\mathbf{n}} \mathrm{CH}_{3}, \mathbf{n}=\mathbf{7 - 1 7}$

Scheme 1 Synthesis of pyridinium hydrazones 2-9 carrying iodide counter anion 
Table 1 Times and yields of halogenated pyridinium hydrazones 2-9 under conventional and ultrasound

\begin{tabular}{|c|c|c|c|c|c|}
\hline \multirow[t]{2}{*}{$\begin{array}{l}\text { Compound } \\
\text { no }\end{array}$} & \multirow[t]{2}{*}{$\mathbf{R}$} & \multicolumn{2}{|c|}{$\begin{array}{l}\text { Conventional } \\
\text { method } \\
\text { CM }\end{array}$} & \multicolumn{2}{|c|}{$\begin{array}{l}\text { Ultrasound method } \\
\text { US }\end{array}$} \\
\hline & & Time (h) & Yield (\%) & Time (h) & Yield (\%) \\
\hline 2 & $\mathrm{C}_{8} \mathrm{H}_{17}$ & 72 & 84 & 10 & 92 \\
\hline 3 & $\mathrm{C}_{9} \mathrm{H}_{19}$ & 72 & 90 & 10 & 96 \\
\hline 4 & $\mathrm{C}_{10} \mathrm{H}_{21}$ & 72 & 88 & 12 & 92 \\
\hline 5 & $\mathrm{C}_{11} \mathrm{H}_{23}$ & 72 & 92 & 12 & 98 \\
\hline 6 & $\mathrm{C}_{12} \mathrm{H}_{25}$ & 72 & 88 & 12 & 92 \\
\hline 7 & $\mathrm{C}_{14} \mathrm{H}_{29}$ & 72 & 85 & 12 & 92 \\
\hline 8 & $\mathrm{C}_{16} \mathrm{H}_{33}$ & 72 & 89 & 12 & 94 \\
\hline 9 & $\mathrm{C}_{18} \mathrm{H}_{37}$ & 72 & 83 & 12 & 96 \\
\hline
\end{tabular}

multiplet between $\delta_{\mathrm{P}}-152.70$ and $-135.76 \mathrm{ppm}$ in the ${ }^{31} \mathrm{P}$ NMR spectra confirmed the presence of $\mathrm{PF}_{6}{ }^{-}$in their structure.

On the other hand, the ${ }^{19} \mathrm{~F}$ NMR analysis of the same compounds revealed the appearance of new doublet at $\delta_{\mathrm{F}}-70.39$ and $-69.21 \mathrm{ppm}$ attributed to the six fluorine atoms in $\mathrm{PF}_{6}{ }^{-}$anions.

The formation of ionic liquids 11, 14, 17, 20, 23, 26, 29 and 32 carrying $\mathrm{BF}_{4}^{-}$in their structures were supported by the ${ }^{11} \mathrm{~B}$ and ${ }^{19} \mathrm{~F}$ NMR experiments. Thus, their ${ }^{11} \mathrm{~B}$ NMR spectra exhibited a multiplet between $\delta_{\mathrm{B}}$ -1.30 and $-1.29 \mathrm{ppm}$ confirming the presence of boron atom in its $\mathrm{BF}_{4}{ }^{-}$form. Two doublets were recorded at $\delta_{\mathrm{F}}$ -149.12 and $-148.12 \mathrm{ppm}$ in their ${ }^{19} \mathrm{~F}$ NMR spectra.

Structural elucidation of the ionic liquids containing trifluoroacetate $\left(\mathrm{CF}_{3} \mathrm{COO}^{-}\right)$was investigated by the ${ }^{19} \mathrm{~F}$ NMR analysis which revealed the presence of characteristic singlet ranging from -73.50 to $-75.30 \mathrm{ppm}$.

The physical (state of product and melting points) and photochemical (fluorescence and $\lambda_{\max }$ in UV) data of the synthesized pyridinium hydrazones 2-33 were investigated and recorded in Table 3.

\section{Biological results}

Attempting to characterize any potential biological activity associated with the newly synthesized compounds, an in vitro assessment of their antiproliferative activity was conducted on four different human cancerous cell lines; the human breast adenocarcinoma (MCF-7), human breast carcinoma (T47D), human colon epithelial (Caco2) and human uterine cervical carcinoma (Hela) cell lines. Only compounds shown in Table 4 demonstrated a reasonably high antiproliferative activity against the model cancer cell lines used.

Remarkably, increasing the length of the hydrophobic chain appears to significantly potentiate the antiproliferative activities associated with the examined analogues, probably owing to their better penetration into the cellular compartment.

To determine the apoptotic effects of cytotoxic compounds and to evaluate modulators of the cell death cascade, activation of the caspase- 3 pathway, a hallmark of apoptosis, can be employed in cellular assays. According to the demonstrated results (Fig. 1) and in response to $48 \mathrm{~h}$ treatment with the most potent compounds, significant increase in caspase- 3 activity is yielded suggesting that the antiproliferative activities of the examined compounds are most likely mediated by an apoptotic cellular death pathway.

Further exploration of possible pathways by which these compounds exert their antiproliferative activities should shed light onto prospective molecular targets with which the compounds may interrelate.

\section{Docking results}

In order to explain the anticancer activity of the verified compounds 2-9 against the examined cancer cell lines, we recruited the crystal structure of PI3K $\alpha$ (PDB ID: 2RD0) [21] to determine the binding interaction of these compounds in PI3K $\alpha$ kinase domain. Noting that these cell lines express phosphatidylinositol 3-kinase (PI3K $\alpha)$ particularly MCF-7 [22-26], T47D [22, 25-32], Caco-2 [33-35] and Hela [36-38].

The binding site of 2RD0 is composed of M772, K776, W780, I800, K802, L807, D810, Y836, I848, E849, V850, V851, S854, T856, Q859, M922, F930, 1932 and D933 [39]. The hydrophobic and polar residues are located in the binding domain. It's worth noting that the exposed hydrophilic and hydrophobic surface areas of the cocrystallized ligand agree with the surrounding residues.

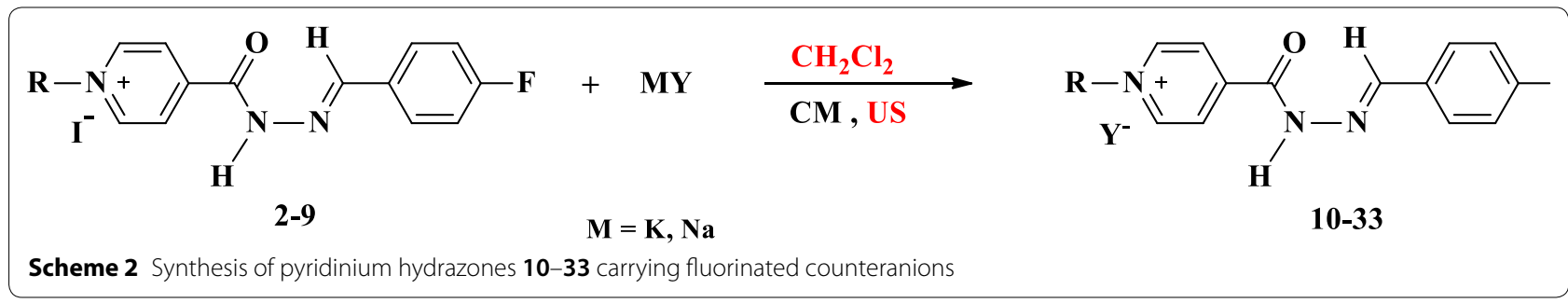


Table 2 Times and yields of pyridinium hydrazones 10-33 carrying fluorinated counter anions under conventional and ultrasound

\begin{tabular}{|c|c|c|c|c|c|c|}
\hline \multirow[t]{2}{*}{ Compound no } & \multirow[t]{2}{*}{$\mathbf{R}$} & \multirow[t]{2}{*}{$Y$} & \multicolumn{2}{|c|}{$\begin{array}{l}\text { Conventional method } \\
\mathrm{CM}\end{array}$} & \multicolumn{2}{|c|}{$\begin{array}{l}\text { Ultrasound method } \\
\text { US }\end{array}$} \\
\hline & & & Time (h) & Yield (\%) & Time (h) & Yield (\%) \\
\hline 10 & $\mathrm{C}_{8} \mathrm{H}_{17}$ & $\mathrm{PF}_{6}$ & 16 & 83 & 6 & 90 \\
\hline 11 & $\mathrm{C}_{8} \mathrm{H}_{17}$ & $\mathrm{BF}_{4}$ & 16 & 98 & 6 & 98 \\
\hline 12 & $\mathrm{C}_{8} \mathrm{H}_{17}$ & $\mathrm{COOCF}_{3}$ & 16 & 80 & 6 & 88 \\
\hline 13 & $\mathrm{C}_{9} \mathrm{H}_{19}$ & $\mathrm{PF}_{6}$ & 16 & 90 & 6 & 94 \\
\hline 14 & $\mathrm{C}_{9} \mathrm{H}_{19}$ & $\mathrm{BF}_{4}$ & 16 & 85 & 6 & 90 \\
\hline 15 & $\mathrm{C}_{9} \mathrm{H}_{19}$ & $\mathrm{COOCF}_{3}$ & 16 & 87 & 6 & 92 \\
\hline 16 & $\mathrm{C}_{10} \mathrm{H}_{21}$ & $\mathrm{PF}_{6}$ & 16 & 98 & 6 & 98 \\
\hline 17 & $\mathrm{C}_{10} \mathrm{H}_{21}$ & $\mathrm{BF}_{4}$ & 16 & 88 & 6 & 90 \\
\hline 18 & $\mathrm{C}_{10} \mathrm{H}_{21}$ & $\mathrm{COOCF}_{3}$ & 16 & 86 & 6 & 92 \\
\hline 19 & $\mathrm{C}_{11} \mathrm{H}_{23}$ & $\mathrm{PF}_{6}$ & 16 & 94 & 6 & 98 \\
\hline 20 & $\mathrm{C}_{11} \mathrm{H}_{23}$ & $\mathrm{BF}_{4}$ & 16 & 93 & 6 & 94 \\
\hline 21 & $\mathrm{C}_{11} \mathrm{H}_{23}$ & $\mathrm{COOCF}_{3}$ & 16 & 90 & 6 & 94 \\
\hline 22 & $\mathrm{C}_{12} \mathrm{H}_{25}$ & $\mathrm{PF}_{6}$ & 16 & 87 & 6 & 90 \\
\hline 23 & $\mathrm{C}_{12} \mathrm{H}_{25}$ & $\mathrm{BF}_{4}$ & 16 & 82 & 6 & 90 \\
\hline 24 & $\mathrm{C}_{12} \mathrm{H}_{25}$ & $\mathrm{COOCF}_{3}$ & 16 & 88 & 6 & 92 \\
\hline 25 & $\mathrm{C}_{14} \mathrm{H}_{29}$ & $\mathrm{PF}_{6}$ & 16 & 95 & 6 & 98 \\
\hline 26 & $\mathrm{C}_{14} \mathrm{H}_{29}$ & $\mathrm{BF}_{4}$ & 16 & 93 & 6 & 96 \\
\hline 27 & $\mathrm{C}_{14} \mathrm{H}_{29}$ & $\mathrm{COOCF}_{3}$ & 16 & 97 & 6 & 98 \\
\hline 28 & $\mathrm{C}_{16} \mathrm{H}_{33}$ & $\mathrm{PF}_{6}$ & 16 & 89 & 6 & 92 \\
\hline 29 & $\mathrm{C}_{16} \mathrm{H}_{33}$ & $\mathrm{BF}_{4}$ & 16 & 90 & 6 & 94 \\
\hline 30 & $\mathrm{C}_{16} \mathrm{H}_{33}$ & $\mathrm{COOCF}_{3}$ & 16 & 88 & 6 & 92 \\
\hline 31 & $\mathrm{C}_{18} \mathrm{H}_{37}$ & $\mathrm{PF}_{6}$ & 16 & 88 & 6 & 92 \\
\hline 32 & $\mathrm{C}_{18} \mathrm{H}_{37}$ & $\mathrm{BF}_{4}$ & 16 & 87 & 6 & 90 \\
\hline 33 & $\mathrm{C}_{18} \mathrm{H}_{37}$ & $\mathrm{COOCF}_{3}$ & 16 & 84 & 6 & 90 \\
\hline
\end{tabular}

The polar residues furnish hydrogen-bonding, ion-dipole and dipole-dipole interactions.

Furthermore, the polar acidic or basic residues mediate an ionic (electrostatic) bonding. The nonpolar motif such as the aromatic and/or hydrophobic residue affords $\pi$-stacking aromatic and hydrophobic (van der Waals) interaction, respectively.

In order to identify the structural-basis of PI3K $\alpha$ / ligand interaction of the verified compounds in the catalytic kinase domain of PI3K $\alpha$, we employed QPLD docking $[40,41]$ against the kinase cleft of 2RD0. Our QPLD docking data show that some of the synthesized molecules 2-9 bind to the kinase domain of PI3K $\alpha$ (Fig. 2, part a). Indeed, compounds having side chain alkyl group more than twelve carbon atoms 7-9 extend beyond the binding cleft boundary.

Moreover, a part of the docked pose of 2 superposes that of the co-crystalized ligand (Fig. 2, part b).

Some of key binding residues are shown and $\mathrm{H}$ atoms are hidden for clarity purpose. Picture is captured by PYMOL. The backbones of 2-9 tend to form H-bond with S774, K802, H917, and D933 (Table 5) (Fig. 3). Additionally, 2-9 showed comparable QPLD binding affinity thus referring that the flexibility of the side-chain carbon atoms might ameliorate the steric effect. Other computational [41-45] and experimental studies [21] reported the significance of these residues in PI3K $\alpha$ /ligand formation.

Noticing that the whole synthesized compounds, 2-18 and 22-23, share the core nucleus but differs in the sidechain carbon atoms number as well as the counterpart anion, for example 2 matches 10, 11, and 12. It's worth noting that the effect of salt enhances compound solubility and assists for better biological investigation.

Contrarily, in silico modeling neglects the effect of the counterpart anion thus we carried out the docking studies for 2-9 as representative models for the whole dataset. Figure 4 shows that there is a positive correlation factor $\left(\mathrm{R}^{2}=0.828\right)$ between the QPLD docking scores against $\mathrm{PI} 3 \mathrm{~K} \alpha$ and $\mathrm{IC}_{50}$.

In order to get further details about the functionalities of 2-9, we screened them against a reported PI3K $\alpha$ inhibitor pharmacophore model [42]. The verified 
Table 3 Physical and analytical data for the newly synthesized pyridinium hydrazones 2-33

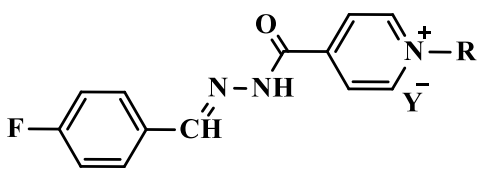

\begin{tabular}{|c|c|c|c|c|c|}
\hline $\begin{array}{l}\text { Comp } \\
\text { no }\end{array}$ & $\mathbf{R}$ & $\mathrm{Y}$ & $\mathrm{mp}{ }^{\circ} \mathrm{C}$ & $\lambda_{\max }(\mathrm{nm})$ & Fluorescence \\
\hline 2 & $\mathrm{C}_{8} \mathrm{H}_{17}$ & I & $104-105$ & $\begin{array}{l}222,330 \\
430\end{array}$ & + \\
\hline 3 & $\mathrm{C}_{9} \mathrm{H}_{19}$ & I & $91-93$ & $\begin{array}{l}220,332 \\
432\end{array}$ & + \\
\hline 4 & $\mathrm{C}_{10} \mathrm{H}_{21}$ & 1 & $110-112$ & $\begin{array}{l}220,332 \\
430\end{array}$ & + \\
\hline 5 & $\mathrm{C}_{11} \mathrm{H}_{23}$ & 1 & $82-83$ & $\begin{array}{l}220,332 \\
430\end{array}$ & + \\
\hline 6 & $\mathrm{C}_{12} \mathrm{H}_{25}$ & 1 & $72-73$ & $\begin{array}{c}220,330 \\
430\end{array}$ & + \\
\hline 7 & $\mathrm{C}_{14} \mathrm{H}_{29}$ & 1 & $86-88$ & $\begin{array}{l}220,332 \\
430\end{array}$ & + \\
\hline 8 & $\mathrm{C}_{16} \mathrm{H}_{33}$ & 1 & $78-80$ & $\begin{array}{l}220,332 \\
430\end{array}$ & + \\
\hline 9 & $\mathrm{C}_{18} \mathrm{H}_{37}$ & 1 & $98-99$ & $\begin{array}{l}220,332 \\
430\end{array}$ & + \\
\hline 10 & $\mathrm{C}_{8} \mathrm{H}_{17}$ & $\mathrm{PF}_{6}$ & $\begin{array}{l}\text { Yellow crystals } \\
64-65\end{array}$ & $\begin{array}{l}220,330 \\
430\end{array}$ & + \\
\hline 11 & $\mathrm{C}_{8} \mathrm{H}_{17}$ & $\mathrm{BF}_{4}$ & $\begin{array}{l}\text { Yellow crystals } \\
80-82\end{array}$ & $\begin{array}{l}220,332 \\
430\end{array}$ & + \\
\hline 12 & $\mathrm{C}_{8} \mathrm{H}_{17}$ & $\mathrm{COOCF}_{3}$ & $\begin{array}{l}\text { Yellow crystals } \\
74-76\end{array}$ & $\begin{array}{l}220,332 \\
430\end{array}$ & + \\
\hline 13 & $\mathrm{C}_{9} \mathrm{H}_{19}$ & $\mathrm{PF}_{6}$ & $\begin{array}{l}\text { Yellow crystals } \\
69-70\end{array}$ & $\begin{array}{l}220,330 \\
428\end{array}$ & + \\
\hline 14 & $\mathrm{C}_{9} \mathrm{H}_{19}$ & $\mathrm{BF}_{4}$ & $\begin{array}{l}\text { Yellow crystals } \\
88-90\end{array}$ & $\begin{array}{l}222,328 \\
426\end{array}$ & + \\
\hline 15 & $\mathrm{C}_{9} \mathrm{H}_{19}$ & $\mathrm{COOCF}_{3}$ & $\begin{array}{l}\text { Yellow crystals } \\
\text { 96-98 }\end{array}$ & $\begin{array}{l}222,332 \\
424\end{array}$ & + \\
\hline 16 & $\mathrm{C}_{10} \mathrm{H}_{21}$ & $\mathrm{PF}_{6}$ & Yellow syrup & $\begin{array}{c}220,330 \\
428\end{array}$ & + \\
\hline 17 & $\mathrm{C}_{10} \mathrm{H}_{21}$ & $\mathrm{BF}_{4}$ & Colorless syrup & $\begin{array}{c}220,330 \\
428\end{array}$ & + \\
\hline 18 & $\mathrm{C}_{10} \mathrm{H}_{21}$ & $\mathrm{COOCF}_{3}$ & Yellow syrup & $\begin{array}{l}222,334 \\
432\end{array}$ & + \\
\hline 19 & $\mathrm{C}_{11} \mathrm{H}_{23}$ & $\mathrm{PF}_{6}$ & Yellow syrup & $\begin{array}{l}220,330 \\
428\end{array}$ & + \\
\hline 20 & $\mathrm{C}_{11} \mathrm{H}_{23}$ & $\mathrm{BF}_{4}$ & Yellow syrup & $\begin{array}{l}220,330 \\
426\end{array}$ & + \\
\hline 21 & $\mathrm{C}_{11} \mathrm{H}_{23}$ & $\mathrm{COOCF}_{3}$ & Colorless syrup & $\begin{array}{l}222,332 \\
430\end{array}$ & + \\
\hline 22 & $\mathrm{C}_{12} \mathrm{H}_{25}$ & $\mathrm{PF}_{6}$ & Yellow syrup & $\begin{array}{l}222,330 \\
430\end{array}$ & + \\
\hline 23 & $\mathrm{C}_{12} \mathrm{H}_{25}$ & $\mathrm{BF}_{4}$ & Yellow syrup & $\begin{array}{l}218,332 \\
430\end{array}$ & + \\
\hline 24 & $\mathrm{C}_{12} \mathrm{H}_{25}$ & $\mathrm{COOCF}_{3}$ & Colorless syrup & $\begin{array}{l}220,336 \\
428\end{array}$ & + \\
\hline
\end{tabular}

compounds 2-9 sparingly match the fingerprint of active PI3K $\alpha$ inhibitors; three out of five functionalities for 2-9 (Fig. 5a, b) whereas two out of five functionalities for 6-9 (Fig. 5c, d). This finding explains their moderate to weak PI3K $\alpha$ inhibitory activity and recommends optimizing the core skeleton of this library aiming to improve the biological activity.

Strikingly, the biological activity of 8-9 would suggest that the hydrophobicity of the attached alkyl group as well as the lipid membrane solubility parameter might affect their attachment to the cell line membrane.

In order to evaluate the performance of QPLD program, we compared the QPLD-docked pose of KWT in the mutant H1047R PI3K $\alpha$ (PDB ID: 3HHM) [46] to its native conformation in the crystal structure. Figure 6 shows the superposition of the QPLD-generated KWT pose and the native conformation in 3HHM. The RMSD for heavy atoms of KWT between QPLD-generated docked pose and the native pose was $0.409 \AA$. This demonstrates that QPLD dock is able to reproduce the native conformation in the crystal structure and can reliably predict the ligand binding conformation.

\section{Experimental}

Apparatus and analysis

The Stuart Scientific SMP1 apparatus (Stuart, Red Hill, UK) was used in recording of the uncorrected melting points.

The SHIMADZU FTIR-8400S spectrometer (SHIMADZU, Boston, MA, USA) was used on the IR measurement.

The Bruker spectrometer (400 and $600 \mathrm{MHz}$, Brucker, Fällanden, Switzerland) was used in the NMR analysis using Tetramethylsilane (TMS) (0.00 ppm) as an internal standard.

The Finnigan LCQ and Finnigan MAT 95XL spectrometers (Finnigan, Darmstadt, Germany) were used in the ESI and EI measurement, respectively.

The Kunshan KQ-250B ultrasound cleaner $(50 \mathrm{kHz}$, 240 W, Kunshan Ultrasonic Instrument, Kunshan, China) was used for carrying out all reactions.

\section{General alkylation procedure for the synthesis of cationic amphiphilic fluorinated pyridinium hydrazones 2-9 Conventional method (CM)}

To a mixture of pyridine hydrazone $\mathbf{1}(1 \mathrm{mmol})$ in acetonitrile $(30 \mathrm{ml})$ was added an appropriate long alkyl iodides with chain ranging from $\mathrm{C}_{8}$ to $\mathrm{C}_{18}(1.5 \mathrm{mmol})$ under stirring. The mixture was refluxed for $72 \mathrm{~h}$, then the solvent was reduced under pressure. The obtained solid was collected by filtration and washed with acetonitrile to give the target ILs 2-9. 
Table 3 (continued)

\begin{tabular}{|c|c|c|c|c|c|}
\hline $\begin{array}{l}\text { Comp } \\
\text { no }\end{array}$ & $\mathbf{R}$ & $Y$ & $\mathrm{mp}{ }^{\circ} \mathrm{C}$ & $\lambda_{\max }(\mathrm{nm})$ & Fluorescence \\
\hline 25 & $\mathrm{C}_{14} \mathrm{H}_{29}$ & $\mathrm{PF}_{6}$ & Yellow syrup & $\begin{array}{c}220,332 \\
428\end{array}$ & + \\
\hline 26 & $\mathrm{C}_{14} \mathrm{H}_{29}$ & $\mathrm{BF}_{4}$ & Yellow syrup & $\begin{array}{c}220,336 \\
430\end{array}$ & + \\
\hline 27 & $\mathrm{C}_{14} \mathrm{H}_{29}$ & $\mathrm{COOCF}_{3}$ & Colorless syrup & $\begin{array}{c}220,330 \\
428\end{array}$ & + \\
\hline 28 & $\mathrm{C}_{16} \mathrm{H}_{33}$ & $\mathrm{PF}_{6}$ & Yellow syrup & $\begin{array}{c}220,338 \\
432\end{array}$ & + \\
\hline 29 & $\mathrm{C}_{16} \mathrm{H}_{33}$ & $\mathrm{BF}_{4}$ & Yellow syrup & $\begin{array}{c}218,332 \\
428\end{array}$ & + \\
\hline 30 & $\mathrm{C}_{16} \mathrm{H}_{33}$ & $\mathrm{COOCF}_{3}$ & Colorless syrup & $\begin{array}{c}220,334 \\
430\end{array}$ & + \\
\hline 31 & $\mathrm{C}_{18} \mathrm{H}_{37}$ & $\mathrm{PF}_{6}$ & Yellow syrup & $\begin{array}{c}220,330 \\
428\end{array}$ & + \\
\hline 32 & $\mathrm{C}_{18} \mathrm{H}_{37}$ & $\mathrm{BF}_{4}$ & Yellow syrup & $\begin{array}{c}220,330 \\
432\end{array}$ & + \\
\hline 33 & $\mathrm{C}_{18} \mathrm{H}_{37}$ & $\mathrm{COOCF}_{3}$ & Colorless syrup & $\begin{array}{c}220,332 \\
430\end{array}$ & + \\
\hline
\end{tabular}

Table $4 \mathrm{IC}_{\mathbf{5 0}}$ values $(\boldsymbol{\mu M})$ on 4 different cancer cell lines

\begin{tabular}{|c|c|c|c|c|}
\hline Code & MCF-7 & T47D & Caco-2 & Hela \\
\hline 4 & $153 \pm 12$ & $145 \pm 10$ & $156 \pm 9$ & $155 \pm 11$ \\
\hline 5 & $136 \pm 7$ & $134 \pm 10$ & $139 \pm 9$ & $142 \pm 6$ \\
\hline 6 & $134 \pm 9$ & $139 \pm 7$ & $139 \pm 9$ & $129 \pm 11$ \\
\hline 7 & $120 \pm 6$ & $123 \pm 7$ & $128 \pm 7$ & $119 \pm 8$ \\
\hline 8 & $61 \pm 5$ & $59 \pm 7$ & $67 \pm 6$ & $68 \pm 5$ \\
\hline 9 & $20 \pm 3$ & $23 \pm 4$ & $18 \pm 3$ & $25 \pm 3$ \\
\hline 16 & $179 \pm 15$ & $172 \pm 13$ & $171 \pm 19$ & $177 \pm 10$ \\
\hline 17 & $176 \pm 12$ & $170 \pm 10$ & $168 \pm 12$ & $177 \pm 11$ \\
\hline 19 & $137 \pm 8$ & $133 \pm 11$ & $139 \pm 6$ & $141 \pm 10$ \\
\hline 20 & $132 \pm 4$ & $139 \pm 9$ & $134 \pm 5$ & $138 \pm 5$ \\
\hline 21 & $178 \pm 10$ & $176 \pm 19$ & $171 \pm 15$ & $169 \pm 17$ \\
\hline 22 & $129 \pm 4$ & $129 \pm 8$ & $125 \pm 9$ & $124 \pm 13$ \\
\hline 23 & $128 \pm 10$ & $120 \pm 9$ & $121 \pm 14$ & $128 \pm 11$ \\
\hline 24 & $131 \pm 10$ & $139 \pm 6$ & $145 \pm 7$ & $132 \pm 12$ \\
\hline 25 & $134 \pm 10$ & $133 \pm 9$ & $132 \pm 5$ & $131 \pm 9$ \\
\hline 26 & $123 \pm 10$ & $127 \pm 15$ & $127 \pm 12$ & $129 \pm 11$ \\
\hline 27 & $67 \pm 4$ & $61 \pm 2$ & $67 \pm 4$ & $68 \pm 6$ \\
\hline 28 & $39 \pm 5$ & $40 \pm 6$ & $32 \pm 4$ & $36 \pm 4$ \\
\hline 29 & $21 \pm 3$ & $20 \pm 4$ & $19 \pm 1$ & $26 \pm 2$ \\
\hline 30 & $45 \pm 6$ & $46 \pm 4$ & $41 \pm 3$ & $48 \pm 6$ \\
\hline 31 & $71 \pm 3$ & $77 \pm 8$ & $74 \pm 5$ & $79 \pm 2$ \\
\hline 32 & $39 \pm 7$ & $34 \pm 4$ & $38 \pm 7$ & $35 \pm 7$ \\
\hline 33 & $41 \pm 5$ & $48 \pm 7$ & $44 \pm 3$ & $49 \pm 5$ \\
\hline
\end{tabular}

Values are expressed as mean \pm SD of three experiments

\section{Ultrasound method (US)}

To a mixture of pyridine hydrazone $\mathbf{1}(1 \mathrm{mmol})$ in acetonitrile $(30 \mathrm{ml})$ was added an appropriate long alkyl iodides with chain ranging from $\mathrm{C}_{8}$ to $\mathrm{C}_{18}(1.5 \mathrm{mmol})$ under stirring. The mixture was irradiated by ultrasound irradiation for $10-12 \mathrm{~h}$. The reaction was processed as described above to give the same target ILs 2-9.

4-(2-(4-Fluorobenzylidene) hydrazinecarbonyl)-1-octylpyridin-1-ium iodide (2) It was obtained as yellow crystals; mp: $104-105{ }^{\circ} \mathrm{C}$. FT-IR (KBr), $\mathrm{cm}^{-1}: \bar{v}=1595$ $(\mathrm{C}=\mathrm{N}), 1670(\mathrm{C}=\mathrm{O}), 2870,2960(\mathrm{Al}-\mathrm{H}), 3071(\mathrm{Ar}-\mathrm{H})$. ${ }^{1} \mathrm{H}$ NMR (400 MHz, DMSO- $\left.d_{6}\right): \delta_{\mathrm{H}}=0.83-0.87(\mathrm{~m}$, $\left.3 \mathrm{H}, \mathrm{CH}_{3}\right), 1.25-1.32\left(\mathrm{~m}, 10 \mathrm{H}, 5 \times \mathrm{CH}_{2}\right), 1.94-1.99(\mathrm{~m}$, $\left.2 \mathrm{H}, \mathrm{NCH}_{2} \mathrm{CH}_{2}\right), 4.68\left(\mathrm{t}, 2 \mathrm{H}, J=8 \mathrm{~Hz}, \mathrm{NCH}_{2}\right), 7.22(\mathrm{t}$, $0.5 \mathrm{H}, J=8 \mathrm{~Hz}, \mathrm{Ar}-\mathbf{H}), 7.34(\mathrm{t}, 1.5 \mathrm{H}, J=8 \mathrm{~Hz}, \mathrm{Ar}-\mathbf{H})$, $7.62(\mathrm{dd}, 0.5 \mathrm{H}, J=4 \mathrm{~Hz}, 8 \mathrm{~Hz}, \mathrm{Ar}-\mathrm{H}), 7.88(\mathrm{dd}, 1.5 \mathrm{H}$, $J=4 \mathrm{~Hz}, 8 \mathrm{~Hz}, \mathrm{Ar}-\mathrm{H}), 8.16(\mathrm{~s}, 0.25 \mathrm{H}, \mathrm{H}-\mathrm{C}=\mathrm{N}), 8.39$ $(\mathrm{d}, 0.5 \mathrm{H}, J=4 \mathrm{~Hz}, \mathrm{Ar}-\mathrm{H}), 8.50(\mathrm{~s}, 0.75 \mathrm{H}, \mathrm{H}-\mathrm{C}=\mathrm{N})$, $8.53(\mathrm{~d}, 1.5 \mathrm{H}, J=8 \mathrm{~Hz}, \mathrm{Ar}-\mathrm{H}), 9.25(\mathrm{~d}, 0.5 \mathrm{H}, J=8 \mathrm{~Hz}$, Ar-H), 9.33 (d, 1.5H, J=4 Hz, Ar-H), 12.47 (bs, $1 \mathrm{H}$, CONH). ${ }^{13} \mathrm{C}$ NMR (100 MHz, DMSO- $\left.d_{6}\right): \delta_{\mathrm{C}}=13.89$ $\left(\mathrm{CH}_{3}\right), 21.99,25.36,25.41,28.30,28.40,30.50,30.63$, $31.08\left(6 \times \mathrm{CH}_{2}\right), 60.95,61.02\left(\mathrm{NCH}_{2}\right), 115.74,115.95$, $116.17,126.14,127.11,129.36,129.44,129.73,129.81$, $130.21,130.24,145.08,145.67,147.33,149.36,149.63$ (Ar-C), 158.76, 162.28, 164.75, $165.21(\mathbf{C}=\mathrm{N}, \mathbf{C}=\mathrm{O})$. ${ }^{19} \mathrm{~F}$ NMR (377 MHz, DMSO- $\left.d_{6}\right): \delta_{\mathrm{F}}=(-109.72$ to $-109.65),(-109.20$ to -109.12$)(2 \mathrm{~m}, 1 \mathrm{~F}, \mathrm{Ar}-\mathrm{F}) . \mathrm{MS}$ (ES) $m / z=483.32\left[\mathrm{M}^{+}\right]$.

4-(2-(4-Fluorobenzylidene) hydrazinecarbonyl)-1-nonylpyridin-1-ium iodide (3) It was obtained as yellow crystals; mp: $91-93{ }^{\circ} \mathrm{C}$. FT-IR (KBr), cm ${ }^{-1}: \bar{v}=1598$ $(\mathrm{C}=\mathrm{N}), 1682(\mathrm{C}=\mathrm{O}), 2872,2969(\mathrm{Al}-\mathrm{H}), 3078(\mathrm{Ar}-\mathrm{H})$. ${ }^{1} \mathrm{H}$ NMR $\left(400 \mathrm{MHz}, \mathrm{DMSO}-d_{6}\right): \delta_{\mathrm{H}}=0.83-0.87(\mathrm{~m}, 3 \mathrm{H}$, $\left.\mathrm{CH}_{3}\right), 1.25-1.32\left(\mathrm{~m}, 12 \mathrm{H}, 6 \times \mathrm{CH}_{2}\right), 1.94-1.99(\mathrm{~m}, 2 \mathrm{H}$, $\mathrm{NCH}_{2} \mathrm{CH}_{2}$ ), 4.69 (dd, 2H, $J=4 \mathrm{~Hz}, 8 \mathrm{~Hz}, \mathrm{NCH}_{2}$ ), 7.25 (dd, $0.5 \mathrm{H}, J=8 \mathrm{~Hz}, 12 \mathrm{~Hz}, \mathrm{Ar}-\mathbf{H}), 7.37(\mathrm{dd}, 1.5 \mathrm{H}, J=8 \mathrm{~Hz}$, $12 \mathrm{~Hz}, \mathrm{Ar}-\mathbf{H}), 7.62(\mathrm{dd}, 0.5 \mathrm{H}, J=4 \mathrm{~Hz}, 8 \mathrm{~Hz}, \mathrm{Ar}-\mathbf{H}), 7.89$ $(\mathrm{dd}, 1.5 \mathrm{H}, J=4 \mathrm{~Hz}, 8 \mathrm{~Hz}, \mathrm{Ar}-\mathrm{H}), 8.15(\mathrm{~s}, 0.25 \mathrm{H}, \mathrm{H}-\mathrm{C}=\mathrm{N})$, $8.40(\mathrm{~d}, 0.5 \mathrm{H}, J=8 \mathrm{~Hz}, \mathrm{Ar}-\mathbf{H}), 8.50(\mathrm{~s}, 0.75 \mathrm{H}, \mathbf{H}-\mathrm{C}=\mathrm{N})$, $8.53(\mathrm{~d}, 1.5 \mathrm{H}, J=8 \mathrm{~Hz}, \mathrm{Ar}-\mathrm{H}), 9.25(\mathrm{~d}, 0.5 \mathrm{H}, J=8 \mathrm{~Hz}$, Ar-H), 9.33 (d, 1.5H, J=8 Hz, Ar-H), $12.46(\mathrm{~s}, 0.75 \mathrm{H}$, CONH), 12.51 (s, 0.25H, CONH). ${ }^{13} \mathrm{C}$ NMR (100 MHz, DMSO- $\left.d_{6}\right): \delta_{\mathrm{C}}=13.92\left(\mathrm{CH}_{3}\right), 22.03,25.36,25.41,28.35$, 28.52, 28.70, 30.51, 30.64, $31.18\left(7 \times \mathrm{CH}_{2}\right), 60.93,61.01$ $\left(\mathrm{NCH}_{2}\right), 115.74,115.96,116.18,126.15,127.11,129.35$, $129.43,129.73,129.82,130.20,130.23,145.06,145.69$, 147.31, 149.33, 149.64 (Ar-C), 158.75, 162.28, 164.76, $165.23(\mathbf{C}=\mathrm{N}, \mathbf{C}=\mathrm{O}) .{ }^{19} \mathrm{~F}$ NMR (377 MHz, DMSO- $\left.d_{6}\right)$ : $\delta_{\mathrm{F}}=(-109.94$ to -109.86$),(-109.42$ to -109.34$)(2 \mathrm{~m}$, $1 \mathrm{~F}, \mathrm{Ar}-\mathbf{F})$. MS (ES) $m / z=497.10\left[\mathrm{M}^{+}\right]$. 


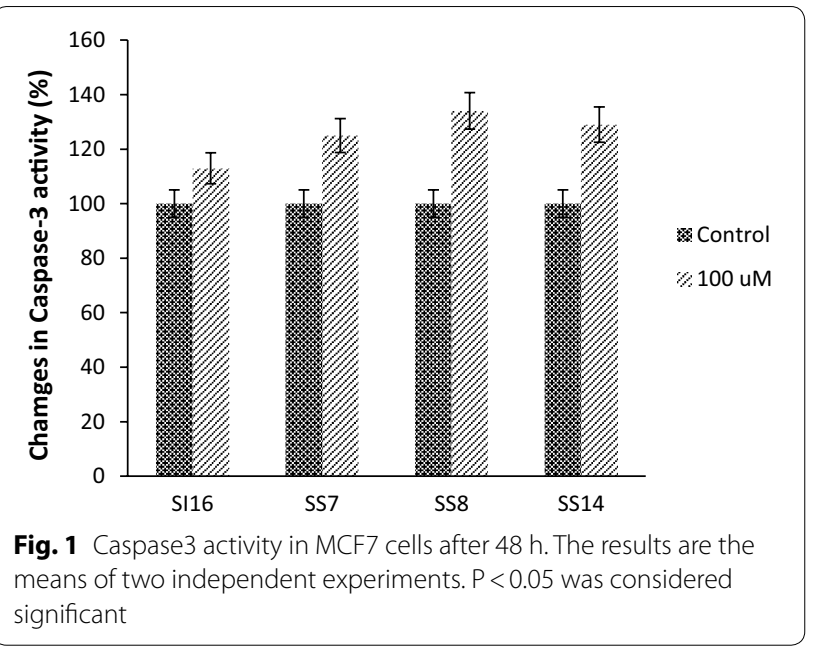

1-Decyl-4-(2-(4-fluorobenzylidene) hydrazinecarbonyl) pyridin-1-ium iodide (4) It was obtained as yellow crystals; mp: $110-112{ }^{\circ} \mathrm{C}$. FT-IR (KBr), $\mathrm{cm}^{-1}: \bar{v}=1615$ $(\mathrm{C}=\mathrm{N}), 1690(\mathrm{C}=\mathrm{O}), 2873,2966(\mathrm{Al}-\mathrm{H}), 3074(\mathrm{Ar}-\mathrm{H})$. ${ }^{1} \mathrm{H}$ NMR $\left(400 \mathrm{MHz}, \mathrm{DMSO}-d_{6}\right): \delta_{\mathrm{H}}=0.83-0.87(\mathrm{~m}$, $\left.3 \mathrm{H}, \mathrm{CH}_{3}\right), 1.25-1.32\left(\mathrm{~m}, 14 \mathrm{H}, 7 \times \mathrm{CH}_{2}\right), 1.94-1.99(\mathrm{~m}$, $\left.2 \mathrm{H}, \mathrm{NCH}_{2} \mathrm{CH}_{2}\right), 4.68\left(\mathrm{t}, 2 \mathrm{H}, J=8 \mathrm{~Hz}, \mathrm{NCH}_{2}\right), 7.23(\mathrm{t}$, $0.5 \mathrm{H}, J=8 \mathrm{~Hz}, \mathrm{Ar}-\mathrm{H}), 7.38(\mathrm{dd}, 1.5 \mathrm{H}, J=8 \mathrm{~Hz}, 12 \mathrm{~Hz}$, Ar-H), $7.62(\mathrm{dd}, 0.5 \mathrm{H}, J=4 \mathrm{~Hz}, 8 \mathrm{~Hz}, \mathrm{Ar}-\mathbf{H}), 7.89$ (dd, $1.5 \mathrm{H}, J=4 \mathrm{~Hz}, 8 \mathrm{~Hz}, \mathrm{Ar}-\mathrm{H}), 8.16(\mathrm{~s}, 0.25 \mathrm{H}, \mathbf{H}-$ $\mathrm{C}=\mathrm{N}), 8.40(\mathrm{~d}, 0.5 \mathrm{H}, J=4 \mathrm{~Hz}, \mathrm{Ar}-\mathrm{H}), 8.50(\mathrm{~s}, 0.75 \mathrm{H}$, $\mathbf{H}-\mathrm{C}=\mathrm{N}), 8.54(\mathrm{~d}, 1.5 \mathrm{H}, J=8 \mathrm{~Hz}, A r-\mathbf{H}), 9.25(\mathrm{~d}$, $0.5 \mathrm{H}, J=4 \mathrm{~Hz}, \mathrm{Ar}-\mathbf{H}), 9.34(\mathrm{~d}, 1.5 \mathrm{H}, J=8 \mathrm{~Hz}, \mathrm{Ar}-\mathbf{H})$, 12.48 (bs, $1 \mathrm{H}, \mathrm{CONH}) .{ }^{13} \mathrm{C}$ NMR $(100 \mathrm{MHz}$, DMSO$\left.d_{6}\right): \delta_{\mathrm{C}}=12.40,12.42\left(\mathrm{CH}_{3}\right), 20.55,23.85,23.89,26.84$, $27.11,27.24,27.28,27.32,28.99,29.13,29.72\left(8 \times \mathrm{CH}_{2}\right)$, 59.42, $59.49\left(\mathrm{NCH}_{2}\right), 114.24,114.46,114.68,124.63$, $125.59,127.84,127.92,128.22,128.31,128.55,128.68$, $128.71,143.54,144.18,145.78,147.80,148.12$ (Ar-C),
Table 5 The QPLD docking scores ( $\mathrm{Kcal} / \mathrm{mol}$ ) and H-bond interactions between the verified compounds 2-9 and PI3Ka

\begin{tabular}{lll}
\hline Compound no & Docking score (Kcal/mol) & H-bond \\
\hline $\mathbf{2}$ & -6.03 & $\mathrm{~K} 802$ \\
$\mathbf{3}$ & -5.93 & $\mathrm{~K} 802$ \\
$\mathbf{4}$ & -5.78 & $\mathrm{D} 933$ \\
$\mathbf{5}$ & -6.16 & $\mathrm{H} 917, \mathrm{D} 933$ \\
$\mathbf{6}$ & -5.69 & $\mathrm{~S} 774, \mathrm{D} 933$ \\
$\mathbf{7}$ & -5.68 & $\mathrm{NA}$ \\
$\mathbf{8}$ & -5.36 & $\mathrm{~K} 802$ \\
$\mathbf{9}$ & -4.58 & $\mathrm{NA}$ \\
\hline
\end{tabular}

157.25, 160.77, 163.24, $163.73(\mathbf{C}=\mathrm{N}, \mathrm{C}=\mathrm{O}) .{ }^{19} \mathrm{~F}$ NMR $\left(377 \mathrm{MHz}, \mathrm{DMSO}-d_{6}\right): \delta_{\mathrm{F}}=(-109.94$ to -109.85$)$, $(-109.42$ to -109.34$)$ (2m, 1F, Ar-F). MS (ES) $\mathrm{m} / z=511.05\left[\mathrm{M}^{+}\right]$.

4-(2-(4-Fluorobenzylidene)hydrazinecarbonyl)-1-undecylpyridin-1-ium iodide (5) It was obtained as yellow crystals; mp: $82-83{ }^{\circ} \mathrm{C}$. FT-IR $(\mathrm{KBr}), \mathrm{cm}^{-1}: \bar{v}=1598$ $(\mathrm{C}=\mathrm{N}), 1677(\mathrm{C}=\mathrm{O}), 2872,2967(\mathrm{Al}-\mathrm{H}), 3078(\mathrm{Ar}-\mathrm{H})$. ${ }^{1} \mathrm{H}$ NMR $\left(400 \mathrm{MHz}, \mathrm{DMSO}-d_{6}\right): \delta_{\mathrm{H}}=0.83-0.87(\mathrm{~m}, 3 \mathrm{H}$, $\left.\mathrm{CH}_{3}\right), 1.24-1.32\left(\mathrm{~m}, 16 \mathrm{H}, 8 \times \mathrm{CH}_{2}\right), 1.96-1.99(\mathrm{~m}, 2 \mathrm{H}$, $\left.\mathrm{NCH}_{2} \mathrm{CH}_{2}\right), 4.68\left(\mathrm{t}, 2 \mathrm{H}, J=8 \mathrm{~Hz}, \mathrm{NCH}_{2}\right), 7.22(\mathrm{t}, 0.5 \mathrm{H}$, $J=8 \mathrm{~Hz}, \mathrm{Ar}-\mathbf{H}), 7.34(\mathrm{t}, 1.5 \mathrm{H}, J=8 \mathrm{~Hz}, \mathrm{Ar}-\mathbf{H}), 7.62(\mathrm{dd}$, $0.5 \mathrm{H}, J=4 \mathrm{~Hz}, 8 \mathrm{~Hz}, \operatorname{Ar}-\mathrm{H}), 7.89$ (dd, $1.5 \mathrm{H}, J=4 \mathrm{~Hz}$, $8 \mathrm{~Hz}, \operatorname{Ar}-\mathrm{H}), 8.16(\mathrm{~s}, 0.25 \mathrm{H}, \mathrm{H}-\mathrm{C}=\mathrm{N}), 8.39(\mathrm{~d}, 0.5 \mathrm{H}$, $J=4 \mathrm{~Hz}, \operatorname{Ar}-\mathbf{H}), 8.50(\mathrm{~s}, 0.75 \mathrm{H}, \mathrm{H}-\mathrm{C}=\mathrm{N}), 8.53(\mathrm{~d}, 1.5 \mathrm{H}$, $J=8 \mathrm{~Hz}, \mathrm{Ar}-\mathbf{H}), 9.25(\mathrm{~d}, 0.5 \mathrm{H}, J=8 \mathrm{~Hz}, \mathrm{Ar}-\mathbf{H}), 9.34(\mathrm{~d}$, $1.5 \mathrm{H}, J=8 \mathrm{~Hz}, \mathrm{Ar}-\mathrm{H}$ ), 12.45 (bs, $1 \mathrm{H}, \mathrm{CONH}) .{ }^{13} \mathrm{C}$ NMR $\left(100 \mathrm{MHz}, \mathrm{DMSO}-d_{6}\right): \delta_{\mathrm{C}}=12.39\left(\mathrm{CH}_{3}\right), 20.53,23.86$, 26.83, 27.13, 27.23, 27.37, 27.40, 28.98, 29.12, 29.74 $\left(9 \times \mathrm{CH}_{2}\right), 59.46,59.53\left(\mathrm{NCH}_{2}\right), 114.23,114.44,114.66$, $124.63,125.61,127.85,127.93,128.22,128.31,128.53$,

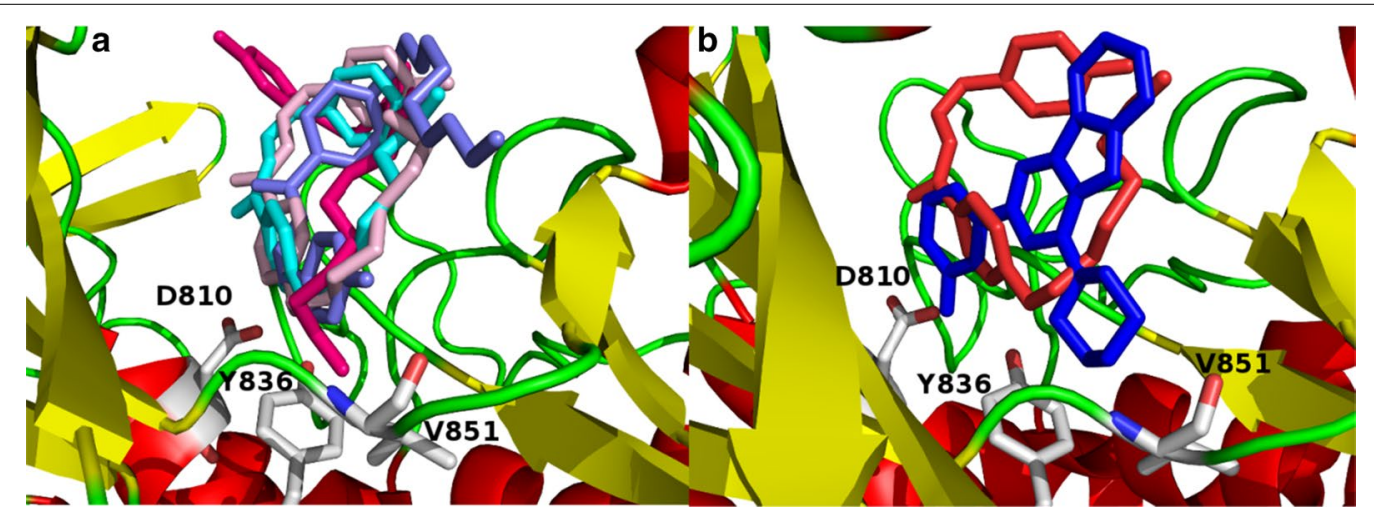

Fig. 2 The catalytic kinase domain of (a) 2RD0 harbors the QPLD docked poses of some of the verified molecules 2-9 and (b) superposition of the QPLD docked pose $\mathbf{2}$ and the co-crystallized ligand represented in red and blue colors, respectively 


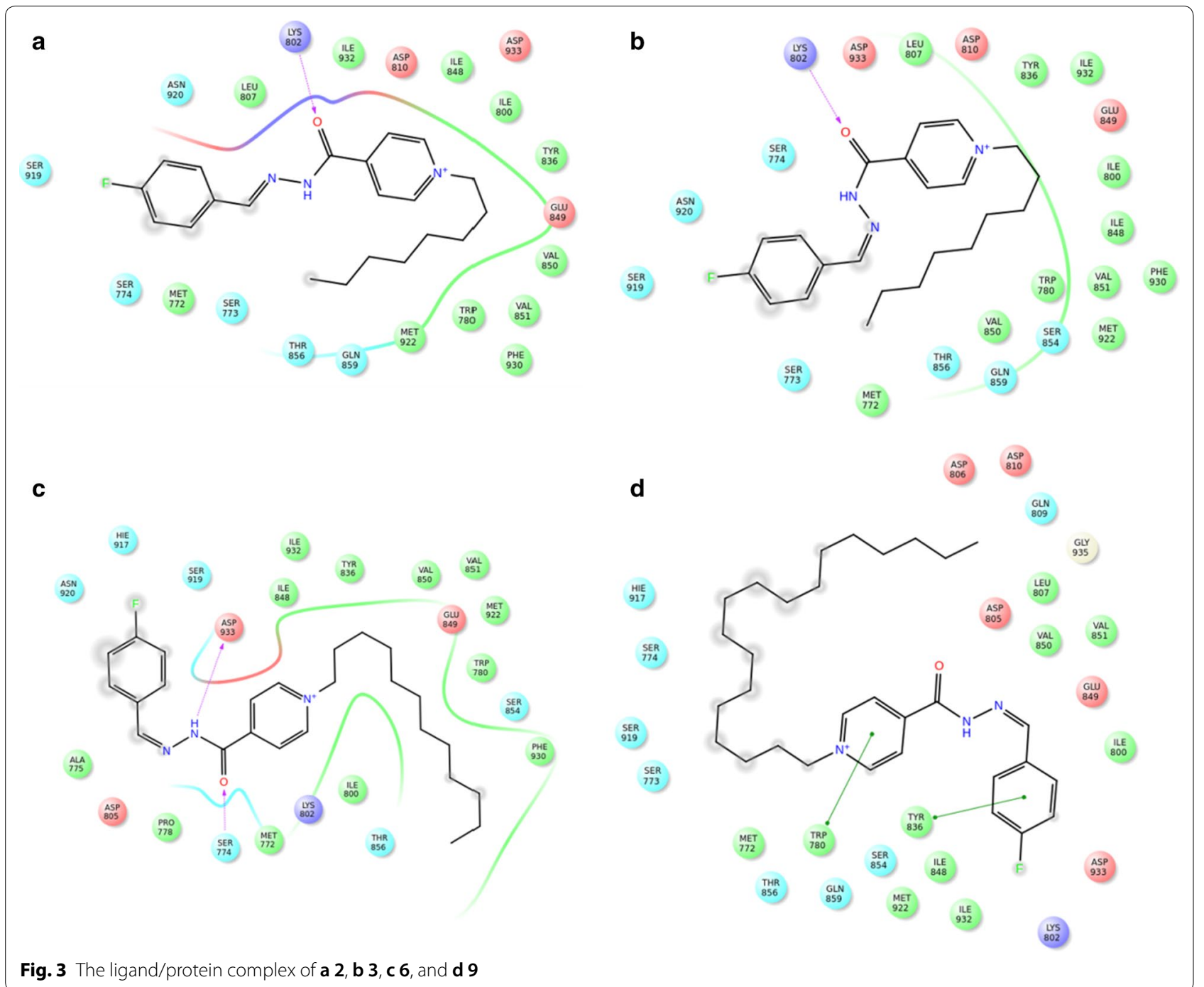

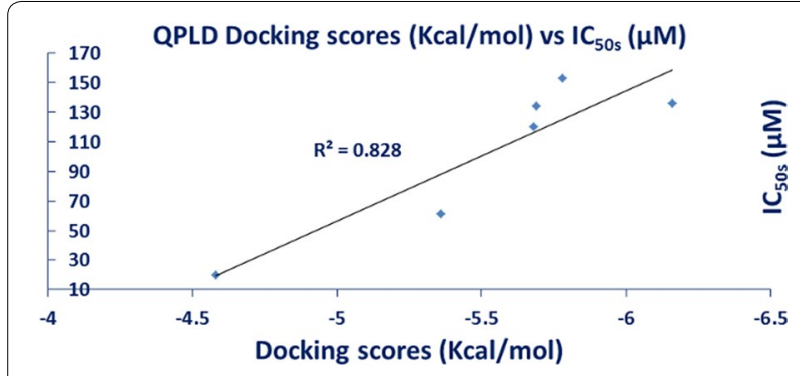

Fig. 4 The correlation between the QPLD docking scores and between $I_{50}$ for the tested compounds

128.56, 128.71, 128.74, 143.58, 144.18, 145.82, 147.88, 148.15 (Ar-C), 157.23, 160.78, 163.26, $163.69(\mathrm{C}=\mathrm{N}$, $\mathrm{C}=\mathrm{O}) .{ }^{19} \mathrm{~F}$ NMR $\left(377 \mathrm{MHz}, \mathrm{DMSO}-d_{6}\right): \delta_{\mathrm{F}}=(-109.95$ to
$-109.88),(-109.35$ to -109.37$)$ (2m, 1F, Ar-F). MS (ES) $m / z=525.10\left[\mathrm{M}^{+}\right]$.

1-Dodecyl-4-(2-(4-fluorobenzylidene) hydrazinecarbonyl)pyridin-1-ium iodide (6) It was obtained as yellow crystals; mp: $72-73{ }^{\circ} \mathrm{C}$. FT-IR (KBr), $\mathrm{cm}^{-1}: \bar{v}=1605$ $(\mathrm{C}=\mathrm{N}), 1688(\mathrm{C}=\mathrm{O}), 2883,2961(\mathrm{Al}-\mathrm{H}), 3074(\mathrm{Ar}-\mathrm{H})$. ${ }^{1} \mathrm{H}$ NMR $\left(400 \mathrm{MHz}, \mathrm{DMSO}-d_{6}\right): \delta_{\mathrm{H}}=0.83-0.87(\mathrm{~m}, 3 \mathrm{H}$, $\left.\mathrm{CH}_{3}\right), 1.24-1.32\left(\mathrm{~m}, 18 \mathrm{H}, 9 \times \mathrm{CH}_{2}\right), 1.96-1.99(\mathrm{~m}, 2 \mathrm{H}$, $\mathrm{NCH}_{2} \mathrm{CH}_{2}$ ), 4.70 (dd, $2 \mathrm{H}, J=4 \mathrm{~Hz}, 8 \mathrm{~Hz}, \mathrm{NCH}_{2}$ ), 7.22 $(\mathrm{t}, 0.5 \mathrm{H}, J=8 \mathrm{~Hz}, \mathrm{Ar}-\mathbf{H}), 7.34(\mathrm{t}, 1.5 \mathrm{H}, J=8 \mathrm{~Hz}, \mathrm{Ar}-\mathbf{H})$, $7.62(\mathrm{dd}, 0.5 \mathrm{H}, J=4 \mathrm{~Hz}, 8 \mathrm{~Hz}, \mathrm{Ar}-\mathbf{H}), 7.88(\mathrm{dd}, 1.5 \mathrm{H}$, $J=4 \mathrm{~Hz}, 8 \mathrm{~Hz}, \mathrm{Ar}-\mathbf{H}), 8.16(\mathrm{~s}, 0.25 \mathrm{H}, \mathbf{H}-\mathrm{C}=\mathrm{N}), 8.39(\mathrm{~d}$, $0.5 \mathrm{H}, J=4 \mathrm{~Hz}, \mathrm{Ar}-\mathbf{H}), 8.50(\mathrm{~s}, 0.75 \mathrm{H}, \mathbf{H}-\mathrm{C}=\mathrm{N}), 8.53(\mathrm{~d}$, $1.5 \mathrm{H}, J=8 \mathrm{~Hz}, \mathrm{Ar}-\mathbf{H}), 9.25$ (d, $0.5 \mathrm{H}, J=4 \mathrm{~Hz}, \mathrm{Ar}-\mathbf{H})$, $9.34(\mathrm{~d}, 1.5 \mathrm{H}, J=8 \mathrm{~Hz}, \mathrm{Ar}-\mathrm{H}), 12.46$ (bs, $1 \mathrm{H}, \mathrm{CONH})$. ${ }^{13} \mathrm{C}$ NMR $\left(100 \mathrm{MHz}, \mathrm{DMSO}-d_{6}\right): \delta_{\mathrm{C}}=11.54,11.59\left(\mathrm{CH}_{3}\right)$, 


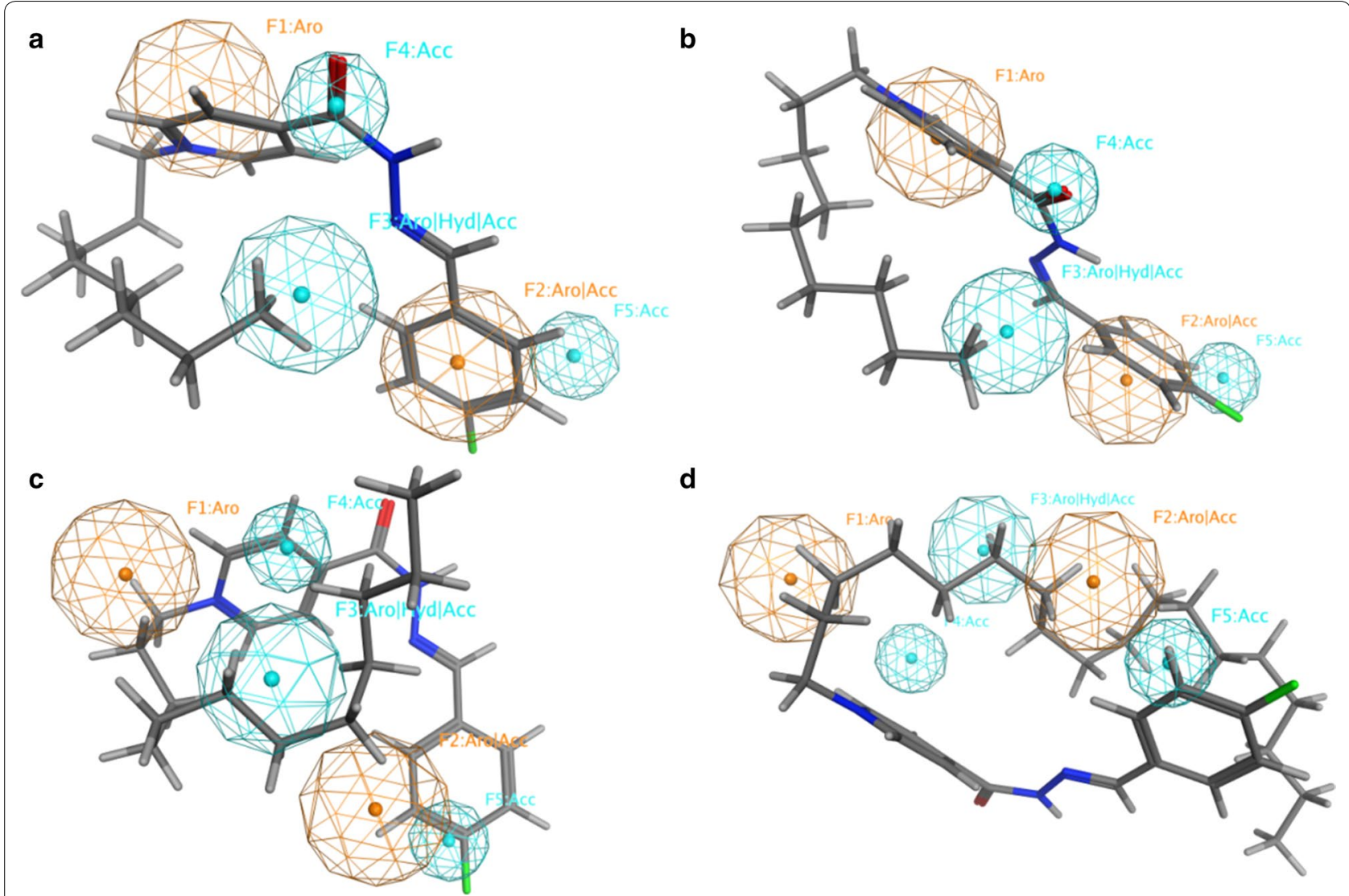

Fig. 5 PI3Ka inhibitor pharmacophore model with a 2, b 3, c 6, and d 9. Aro stands for aromatic ring; Acc for H-bond acceptor; and Hyd for hydrophobic group. Picture made by $\mathrm{MOE}^{52}$

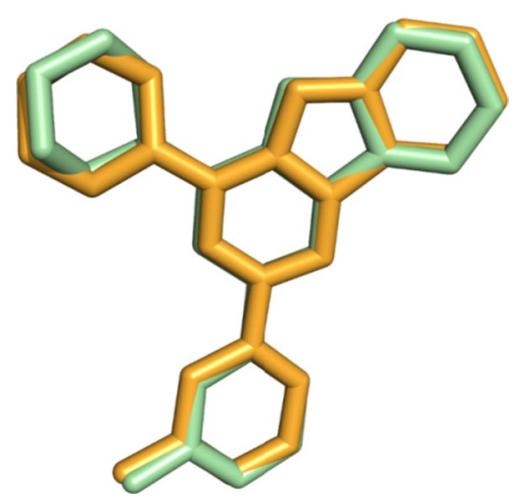

Fig. 6 The superposition of KWT QPLD-docked pose and its native conformation in $3 \mathrm{HHM}$. The native coordinates are represented in orange and the docked pose in green color. Picture visualized by PYMOL

$19.68,23.00,25.98,26.30,26.38,26.51,26.60,28.13$, 28.27, $28.88\left(10 \times \mathrm{CH}_{2}\right), 58.60,58.67\left(\mathrm{NCH}_{2}\right), 113.37$, $113.59,113.80,123.78,124.75,127.00,127.08,127.36$, $127.45,127.86,127.89,142.72,143.33,144.97,147.02$,
$127.29(\mathrm{Ar}-\mathrm{C}), 156.38,159.93,162.40,162.83(\mathrm{C}=\mathrm{N}$, $\mathrm{C}=\mathrm{O}) .{ }^{19} \mathrm{~F}$ NMR $\left(377 \mathrm{MHz}, \mathrm{DMSO}-d_{6}\right): \delta_{\mathrm{F}}=(-109.95$ to $-109.88),(-109.44$ to -109.36$)(2 \mathrm{~m}, 1 \mathrm{~F}, \mathrm{Ar}-\mathrm{F})$. MS (ES) $m / z=539.40\left[\mathrm{M}^{+}\right]$.

4-(2-(4-Fluorobenzylidene)hydrazinecarbonyl)-1-tetradecylpyridin-1-ium iodide (7) It was obtained as yellow crystals; mp: $86-88{ }^{\circ} \mathrm{C}$. FT-IR $(\mathrm{KBr}), \mathrm{cm}^{-1}: \overline{\mathrm{v}}=1590$ $(\mathrm{C}=\mathrm{N}), 1679(\mathrm{C}=\mathrm{O}), 2878,2964(\mathrm{Al}-\mathrm{H}), 3078(\mathrm{Ar}-\mathrm{H})$. ${ }^{1} \mathrm{H}$ NMR $\left(400 \mathrm{MHz}\right.$, DMSO- $\left.d_{6}\right): \delta_{\mathrm{H}}=0.83-0.86(\mathrm{~m}$, $\left.3 \mathrm{H}, \mathrm{CH}_{3}\right), 1.24-1.32\left(\mathrm{~m}, 22 \mathrm{H}, 11 \times \mathrm{CH}_{2}\right), 1.94-1.98(\mathrm{~m}$, $\left.2 \mathrm{H}, \mathrm{NCH}_{2} \mathrm{CH}_{2}\right), 4.68\left(\mathrm{t}, 2 \mathrm{H}, J=8 \mathrm{~Hz}, \mathrm{NCH}_{2}\right), 7.22(\mathrm{t}$, $0.5 \mathrm{H}, J=8 \mathrm{~Hz}, \mathrm{Ar}-\mathbf{H}), 7.34(\mathrm{t}, 1.5 \mathrm{H}, J=8 \mathrm{~Hz}, \mathrm{Ar}-\mathbf{H})$, $7.62(\mathrm{dd}, 0.5 \mathrm{H}, J=4 \mathrm{~Hz}, 8 \mathrm{~Hz}, \mathrm{Ar}-\mathrm{H}), 7.89(\mathrm{dd}, 1.5 \mathrm{H}$, $J=4 \mathrm{~Hz}, 8 \mathrm{~Hz}, \mathrm{Ar}-\mathbf{H}), 8.16(\mathrm{~s}, 0.25 \mathrm{H}, \mathrm{H}-\mathrm{C}=\mathrm{N}), 8.39(\mathrm{~d}$, $0.5 \mathrm{H}, J=4 \mathrm{~Hz}, \mathrm{Ar}-\mathrm{H}), 8.50(\mathrm{~s}, 0.75 \mathrm{H}, \mathrm{H}-\mathrm{C}=\mathrm{N}), 8.53(\mathrm{~d}$, $1.5 \mathrm{H}, J=8 \mathrm{~Hz}, \operatorname{Ar}-\mathbf{H}), 9.25(\mathrm{~d}, 0.5 \mathrm{H}, J=8 \mathrm{~Hz}, \mathrm{Ar}-\mathbf{H})$, $9.33(\mathrm{~d}, 1.5 \mathrm{H}, J=4 \mathrm{~Hz}, \mathrm{Ar}-\mathrm{H}), 12.44(\mathrm{~s}, 0.75 \mathrm{H}, \mathrm{CONH})$, 12.49 (s, 0.25H, CONH). ${ }^{13} \mathrm{C}$ NMR $(100 \mathrm{MHz}$, DMSO$\left.d_{6}\right): \delta_{\mathrm{C}}=13.89\left(\mathrm{CH}_{3}\right), 22.03,25.36,27.80,28.34,28.65$, $28.74,28.86,28.96,28.99,29.77,30.48,30.62,31.24$, $32.85\left(12 \times \mathrm{CH}_{2}\right), 60.96,61.03\left(\mathrm{NCH}_{2}\right), 115.73,115.94$, 
$116.16,126.13,127.11,129.34,129.43,129.72,129.81$, $130.21,130.24,145.08,145.68,147.31,149.38,149.65$ (Ar-C), 158.73, 162.29, 164.29, $165.18(\mathbf{C}=\mathrm{N}, \mathbf{C}=\mathrm{O})$. ${ }^{19} \mathrm{~F}$ NMR (377 MHz, DMSO- $\left.d_{6}\right): \delta_{\mathrm{F}}=(-109.96$ to $-109.89)$, (-109.44 to -109.36$)$ (2m, 1F, Ar-F). MS (ES) $m / z=567.20\left[\mathrm{M}^{+}\right]$.

4-(2-(4-Fluorobenzylidene)hydrazinecarbonyl)-1-hexadecylpyridin-1-ium iodide (8) It was obtained as yellow crystals; mp: $78-80{ }^{\circ} \mathrm{C}$. FT-IR $(\mathrm{KBr}), \mathrm{cm}^{-1}: \bar{v}=1610(\mathrm{C}=\mathrm{N})$, $1677(\mathrm{C}=\mathrm{O}), 2887,2969(\mathrm{Al}-\mathrm{H}), 3076(\mathrm{Ar}-\mathrm{H}) .{ }^{1} \mathrm{H}$ NMR $\left(400 \mathrm{MHz}, \mathrm{DMSO}-d_{6}\right): \delta_{\mathrm{H}}=0.83-0.86\left(\mathrm{~m}, 3 \mathrm{H}, \mathrm{CH}_{3}\right), 1.23-$ $1.30\left(\mathrm{~m}, 26 \mathrm{H}, 13 \times \mathrm{CH}_{2}\right), 1.96-1.98\left(\mathrm{~m}, 2 \mathrm{H}, \mathrm{NCH}_{2} \mathrm{CH}_{2}\right)$, $4.68\left(\mathrm{t}, 2 \mathrm{H}, J=8 \mathrm{~Hz}, \mathrm{NCH}_{2}\right), 7.22(\mathrm{t}, 0.5 \mathrm{H}, J=8 \mathrm{~Hz}, \mathrm{Ar}-\mathbf{H})$, $7.34(\mathrm{t}, 1.5 \mathrm{H}, J=8 \mathrm{~Hz}, \mathrm{Ar}-\mathrm{H}), 7.62(\mathrm{dd}, 0.5 \mathrm{H}, J=4 \mathrm{~Hz}, 8 \mathrm{~Hz}$, Ar-H), 7.89 (dd, 1.5H, J=4 Hz, $8 \mathrm{~Hz}, \mathrm{Ar}-\mathrm{H}), 8.16(\mathrm{~s}, 0.25 \mathrm{H}$, $\mathbf{H}-\mathrm{C}=\mathrm{N}), 8.39(\mathrm{~d}, 0.5 \mathrm{H}, J=4 \mathrm{~Hz}, \mathrm{Ar}-\mathrm{H}), 8.50(\mathrm{~s}, 0.75 \mathrm{H}, \mathbf{H}-$ $\mathrm{C}=\mathrm{N}), 8.53(\mathrm{~d}, 1.5 \mathrm{H}, J=8 \mathrm{~Hz}, \mathrm{Ar}-\mathrm{H}), 9.25(\mathrm{~d}, 0.5 \mathrm{H}, J=8 \mathrm{~Hz}$, $\mathrm{Ar}-\mathrm{H}), 9.34(\mathrm{~d}, 1.5 \mathrm{H}, J=4 \mathrm{~Hz}, \mathrm{Ar}-\mathrm{H}), 12.45(\mathrm{~s}, 0.75 \mathrm{H}$, CONH), 12.49 (s, 0.25H, CONH). ${ }^{13} \mathrm{C}$ NMR (100 MHz, DMSO- $\left.d_{6}\right): \delta_{\mathrm{C}}=13.88\left(\mathrm{CH}_{3}\right), 22.03,25.36,28.34,28.64$, 28.74, 28.87, 28.96, 29.00, 30.49, 30.62, 31.24 $\left(12 \times \mathrm{CH}_{2}\right)$, 60.96, $61.03\left(\mathrm{NCH}_{2}\right), 115.73,115.94,116.16,126.14,127.11$, $129.34,129.43,129.72,129.81,130.04,130.24,145.08$, 145.69, 147.31, 149.37 (Ar-C), 158.72, 162.29, 164.76, $165.18(\mathbf{C}=\mathrm{N}, \mathbf{C}=\mathrm{O}) .{ }^{19} \mathrm{~F}$ NMR (377 MHz, DMSO- $\left.d_{6}\right)$ : $\delta_{\mathrm{F}}=(-109.97$ to -109.89$),(-109.45$ to -109.37$)(2 \mathrm{~m}, 1 \mathrm{~F}$, $\mathrm{Ar}-\mathbf{F})$. MS (ES) $m / z=595.30\left[\mathrm{M}^{+}\right]$.

4-(2-(4-Fluorobenzylidene)hydrazinecarbonyl)-1-octadecylpyridin-1-ium iodide (9) It was obtained as yellow crystals; mp: $98-99{ }^{\circ} \mathrm{C}$. FT-IR $(\mathrm{KBr}), \mathrm{cm}^{-1}: \overline{\mathrm{v}}=1612(\mathrm{C}=\mathrm{N})$, $1678(\mathrm{C}=\mathrm{O}), 2887,2955(\mathrm{Al}-\mathrm{H}), 3086(\mathrm{Ar}-\mathrm{H}) .{ }^{1} \mathrm{H}$ NMR $\left(400 \mathrm{MHz}, \mathrm{CDCl}_{3}\right): \delta_{\mathrm{H}}=0.79-0.82\left(\mathrm{~m}, 3 \mathrm{H}, \mathrm{CH}_{3}\right), 1.16-1.20$ (m, 30H, 15× $\mathrm{CH}_{2}$ ), 1.96-2.00 (m, 2H, $\mathrm{NCH}_{2} \mathrm{CH}_{2}$ ), 4.78 (dd, $\left.2 \mathrm{H}, J=4 \mathrm{~Hz}, 8 \mathrm{~Hz}, \mathrm{NCH}_{2}\right), 6.97(\mathrm{t}, 2 \mathrm{H}, J=8 \mathrm{~Hz}, \mathrm{Ar}-\mathbf{H}), 7.71$ (dd, $2 \mathrm{H}, J=4 \mathrm{~Hz}, 8 \mathrm{~Hz}, \mathrm{Ar}-\mathbf{H}), 8.87$ (d, $2 \mathrm{H}, J=4 \mathrm{~Hz}, \mathrm{Ar}-\mathbf{H})$, $9.08(\mathrm{~s}, 1 \mathrm{H}, \mathbf{H}-\mathrm{C}=\mathrm{N}), 9.12(\mathrm{~d}, 2 \mathrm{H}, J=8 \mathrm{~Hz}, \mathrm{Ar}-\mathbf{H}), 12.18$ (bs, $1 \mathrm{H}, \mathrm{CONH}) \cdot{ }^{13} \mathrm{C}$ NMR $\left(100 \mathrm{MHz}, \mathrm{CDCl}_{3}\right): \delta_{\mathrm{C}}=14.08$ $\left(\mathrm{CH}_{3}\right), 22.66,26.10,28.96,29.31,29.33,29.48,29.57,29.63$, 29.68, 31.67, $31.90\left(16 \times \mathrm{CH}_{2}\right), 62.74\left(\mathrm{NCH}_{2}\right), 115.85,116.07$, $127.88,129.47,130.14,130.22,144.82,147.91,151.67$ (ArC), 158.57, 163.22, 163.25, $165.76(\mathbf{C}=\mathrm{N}, \mathbf{C}=\mathrm{O}) .{ }^{19} \mathrm{~F}$ NMR $\left(377 \mathrm{MHz}, \mathrm{CDCl}_{3}\right): \delta_{\mathrm{F}}=(-107.98$ to -107.89$),(-107.72$ to $-107.65)(2 \mathrm{~m}, 1 \mathrm{~F}, \mathrm{Ar}-\mathrm{F})$. MS (ES) $m / z=623.30\left[\mathrm{M}^{+}\right]$.

\section{General metathesis procedure for the synthesis of pyridinium hydrazones 10-33 Conventional method (CM)}

A mixture of equimolar of IL 2-9 $(1 \mathrm{mmol})$ and fluorinated metal salt $\left(\mathrm{KPF}_{6}, \mathrm{NaBF}_{4}\right.$ and/or $\left.\mathrm{NaCF}_{3} \mathrm{COO}\right)$
(1 mmol) in dichloromethane $(15 \mathrm{ml})$ was heated under reflux for $12 \mathrm{~h}$. After cooling, the solid formed was collected by extraction and/or by filtration. The solid was washed by dichloromethane to afford the task-specific ILs 10-33.

\section{Ultrasound method (US)}

A mixture of equimolar of IL 2-9 (1 mmol) and fluorinated metal salt $\left(\mathrm{KPF}_{6}, \mathrm{NaBF}_{4}\right.$ and/or $\left.\mathrm{NaCF}_{3} \mathrm{COO}\right)$ ( $1 \mathrm{mmol})$ in dichloromethane $(15 \mathrm{ml})$ was irradiated by ultrasound irradiation for $6 \mathrm{~h}$. The reaction was processed as described above to give the same task-specific ILs 10-33.

4-(2-(4-Fluorobenzylidene) hydrazinecarbonyl)-1-octylpyridin-1-ium hexafluorophosphate (10) It was obtained as yellow crystals; mp: $64-65{ }^{\circ} \mathrm{C}$. ${ }^{1} \mathrm{H}$ NMR $\left(400 \mathrm{MHz}, \mathrm{DMSO}-d_{6}\right): \delta_{\mathrm{H}}=0.82-0.88\left(\mathrm{~m}, 3 \mathrm{H}, \mathrm{CH}_{3}\right)$, 1.26-1.30 (m, 10H, $\left.5 \times \mathrm{CH}_{2}\right), \quad 1.94-2.00(\mathrm{~m}, 2 \mathrm{H}$, $\mathrm{NCH}_{2} \mathrm{CH}_{2}$ ), $4.68\left(\mathrm{t}, 2 \mathrm{H}, J=8 \mathrm{~Hz}, \mathrm{NCH}_{2}\right), 7.26(\mathrm{dd}, 0.5 \mathrm{H}$, $J=8 \mathrm{~Hz}, 12 \mathrm{~Hz}, \mathrm{Ar}-\mathbf{H}), 7.38(\mathrm{dd}, 1.5 \mathrm{H}, J=8 \mathrm{~Hz}, 12 \mathrm{~Hz}$, Ar-H), $7.62(\mathrm{dd}, 0.5 \mathrm{H}, J=4 \mathrm{~Hz}, 8 \mathrm{~Hz}, \mathrm{Ar}-\mathbf{H}), 7.89$ (dd, $1.5 \mathrm{H}, J=4 \mathrm{~Hz}, 8 \mathrm{~Hz}, \mathrm{Ar}-\mathbf{H}), 8.16(\mathrm{~s}, 0.25 \mathrm{H}, \mathbf{H}-\mathrm{C}=\mathrm{N})$, $8.40(\mathrm{~d}, 0.5 \mathrm{H}, J=4 \mathrm{~Hz}, \mathrm{Ar}-\mathrm{H}), 8.50(\mathrm{~s}, 0.75 \mathrm{H}, \mathrm{H}-\mathrm{C}=\mathrm{N})$, $8.53(\mathrm{~d}, 1.5 \mathrm{H}, J=4 \mathrm{~Hz}, \mathrm{Ar}-\mathrm{H}), 9.25(\mathrm{~d}, 0.5 \mathrm{H}, J=4 \mathrm{~Hz}$, Ar-H), 9.33 (d, 1.5H, J=4 Hz, Ar-H), 12.50 (bs, $1 \mathrm{H}$, CONH $).{ }^{13} \mathrm{C}$ NMR (100 MHz, DMSO- $\left.d_{6}\right): \delta_{\mathrm{C}}=13.09$ $\left(\mathrm{CH}_{3}\right), 22.00,25.36,25.41,28.30,28.40,30.51,30.64$, $31.09\left(6 \times \mathrm{CH}_{2}\right), 60.95,61.02\left(\mathrm{NCH}_{2}\right), 115.75,115.96$, $116.18,126.14,127.11,129.35,129.44,129.73,129.81$, $130.05,130.24,130.24,145.06,145.67,147.35,149.35$, 149.63 (Ar-C), 158.78, 162.28, 164.75, $165.22(\mathbf{C}=\mathrm{N}$, $\mathrm{C}=\mathrm{O}) .{ }^{31} \mathrm{P}$ NMR $\left(162 \mathrm{MHz}, \mathrm{DMSO}-d_{6}\right): \delta_{\mathrm{P}}=-152.70$ to $-135.29\left(\mathrm{~m}, 1 \mathrm{P}, \mathrm{PF}_{6}\right) .{ }^{19} \mathrm{~F}$ NMR (377 MHz, DMSO- $\left.d_{6}\right)$ : $\delta_{\mathrm{F}}=-69.98\left(\mathrm{~d}, 6 \mathrm{~F}, \mathrm{PF}_{\mathbf{6}}\right),(-109.72$ to -109.65$),(-109.20$ to -109.12 ) (2m, $1 \mathrm{~F}, \mathrm{Ar}-\mathrm{F})$. MS (ES) $m / z=501.20\left[\mathrm{M}^{+}\right]$.

4-(2-(4-Fluorobenzylidene) hydrazinecarbonyl)-1-octylpyridin-1-ium tetrafluoroborate (11) It was obtained as yellow crystals; mp: $80-82{ }^{\circ} \mathrm{C}$. ${ }^{1} \mathrm{H}$ NMR $(400 \mathrm{MHz}$, DMSO- $\left.d_{6}\right): \delta_{\mathrm{H}}=0.84-0.88\left(\mathrm{~m}, 3 \mathrm{H}, \mathrm{CH}_{3}\right), 1.26-1.31$ $\left(\mathrm{m}, 10 \mathrm{H}, 5 \times \mathrm{CH}_{2}\right), 1.95-2.00\left(\mathrm{~m}, 2 \mathrm{H}, \mathrm{NCH}_{2} \mathrm{CH}_{2}\right), 4.70$ (dd, $\left.2 \mathrm{H}, J=4 \mathrm{~Hz}, 8 \mathrm{~Hz}, \mathrm{NCH}_{2}\right), 7.26(\mathrm{dd}, 0.5 \mathrm{H}, J=8 \mathrm{~Hz}$, $12 \mathrm{~Hz}, \mathrm{Ar}-\mathbf{H}), 7.38(\mathrm{dd}, 1.5 \mathrm{H}, J=8 \mathrm{~Hz}, 12 \mathrm{~Hz}, \mathrm{Ar}-\mathbf{H})$, $7.63(\mathrm{dd}, 0.5 \mathrm{H}, J=4 \mathrm{~Hz}, 8 \mathrm{~Hz}, \mathrm{Ar}-\mathrm{H}), 7.90(\mathrm{dd}, 1.5 \mathrm{H}$, $J=4 \mathrm{~Hz}, 8 \mathrm{~Hz}, \mathrm{Ar}-\mathrm{H}), 8.16(\mathrm{~s}, 0.25 \mathrm{H}, \mathrm{H}-\mathrm{C}=\mathrm{N}), 8.41$ $(\mathrm{d}, 0.5 \mathrm{H}, J=8 \mathrm{~Hz}, \mathrm{Ar}-\mathbf{H}), 8.51(\mathrm{~s}, 0.75 \mathrm{H}, \mathbf{H}-\mathrm{C}=\mathrm{N})$, $8.54(\mathrm{~d}, 1.5 \mathrm{H}, J=4 \mathrm{~Hz}, \mathrm{Ar}-\mathbf{H}), 9.27$ (d, 0.5H, $J=8 \mathrm{~Hz}$, $\mathrm{Ar}-\mathrm{H}), 9.36(\mathrm{~d}, 1.5 \mathrm{H}, J=8 \mathrm{~Hz}, \mathrm{Ar}-\mathrm{H}), 12.49(\mathrm{~s}, 0.75 \mathrm{H}$, CONH), 12.53 (s, 0.25H, CONH). ${ }^{13} \mathrm{C}$ NMR (100 MHz, DMSO- $\left.d_{6}\right): \delta_{\mathrm{C}}=13.87\left(\mathrm{CH}_{3}\right), 21.97,25.32,25.38,28.27$, 28.37, 28.40, 30.48, 30.61, $31.06\left(6 \times \mathrm{CH}_{2}\right), 60.89,60.96$ 
$\left(\mathrm{NCH}_{2}\right), 115.71,115.92,116.14,126.10,127.07,129.33$, $129.41,129.69,129.78,130.01,130.15,130.18,145.02$, 145.65, 147.23, 149.28, 149.57 (Ar-C), 158.72, 161.89, 162.23, 164.70, $165.19(\mathbf{C}=\mathrm{N}, \mathbf{C}=\mathrm{O}) .{ }^{11} \mathrm{~B}$ NMR $(128 \mathrm{MHz}$, DMSO- $\left.d_{6}\right): \delta_{\mathrm{B}}=-1.31$ to $-1.30\left(\mathrm{~m}, 1 \mathrm{~B}, \mathrm{BF}_{4}\right) \cdot{ }^{19} \mathrm{~F}$ NMR $\left(377 \mathrm{MHz}, \mathrm{DMSO}-d_{6}\right): \delta_{\mathrm{F}}=(-109.82$ to -109.74$)$, $(-109.29$ to -109.21$)(2 \mathrm{~m}, 1 \mathrm{~F}, \mathrm{Ar}-\mathbf{F}) ;-148.12,-148.07$ $\left(2 \mathrm{~d}, 4 \mathrm{~F}, \mathrm{BF}_{4}\right) . \mathrm{MS}(\mathrm{ES}) \mathrm{m} / z=443.20\left[\mathrm{M}^{+}\right]$.

4-(2-(4-Fluorobenzylidene) hydrazinecarbonyl)-1-octylpyridin-1-ium trifluoroacetate (12) It was obtained as yellow crystals; mp: $74-76{ }^{\circ} \mathrm{C} .{ }^{1} \mathrm{H}$ NMR $(400 \mathrm{MHz}$, DMSO- $\left.d_{6}\right): \delta_{\mathrm{H}}=0.84-0.88\left(\mathrm{~m}, 3 \mathrm{H}, \mathrm{CH}_{3}\right), 1.26-1.30$ (m, $10 \mathrm{H}, 5 \times \mathrm{CH}_{2}$ ), 1.95-1.97 (m, 2H, $\left.\mathrm{NCH}_{2} \mathrm{CH}_{2}\right), 4.69$ $\left(\mathrm{dd}, 2 \mathrm{H}, J=4 \mathrm{~Hz}, 8 \mathrm{~Hz}, \mathrm{NCH}_{2}\right), 7.26(\mathrm{dd}, 0.5 \mathrm{H}, J=8 \mathrm{~Hz}$, $12 \mathrm{~Hz}, \mathrm{Ar}-\mathbf{H}$ ), 7.35 (t, 1.5H, J=8 Hz, Ar-H), 7.62 (dd, $0.5 \mathrm{H}, J=4 \mathrm{~Hz}, 8 \mathrm{~Hz}, \mathrm{Ar}-\mathrm{H}), 7.88(\mathrm{dd}, 1.5 \mathrm{H}, J=4 \mathrm{~Hz}$, $8 \mathrm{~Hz}, \mathrm{Ar}-\mathbf{H}), 8.16(\mathrm{~s}, 0.25 \mathrm{H}, \mathrm{H}-\mathrm{C}=\mathrm{N}), 8.40(\mathrm{~d}, 0.5 \mathrm{H}$, $J=4 \mathrm{~Hz}, \mathrm{Ar}-\mathbf{H}), 8.49(\mathrm{~s}, 0.75 \mathrm{H}, \mathrm{H}-\mathrm{C}=\mathrm{N}), 8.54(\mathrm{~d}, 1.5 \mathrm{H}$, $J=8 \mathrm{~Hz}, \mathrm{Ar}-\mathbf{H}), 9.25$ (d, 0.5H, $J=4 \mathrm{~Hz}, \mathrm{Ar}-\mathbf{H}), 9.32$ (d, $1.5 \mathrm{H}, J=8 \mathrm{~Hz}, \mathrm{Ar}-\mathbf{H}), 12.54$ (bs, $1 \mathrm{H}, \mathrm{CONH}) .{ }^{13} \mathrm{C}$ NMR $\left(100 \mathrm{MHz}, \mathrm{DMSO}-d_{6}\right): \delta_{\mathrm{C}}=13.85\left(\mathrm{CH}_{3}\right), 21.95,25.30$, 25.35, 28.25, 28.35, 28.38, 30.46, 30.58, $31.03\left(6 \times \mathrm{CH}_{2}\right)$, $60.85,60.88\left(\mathrm{NCH}_{2}\right), 115.69,115.88,116.10,126.05$, $127.04,129.28,129.36,129.61,129.70,129.99,130.24$, 130.27, 144.98, 145.54, 147.59, 149.20, 149.56 (Ar-C), 158.84, 162.15, $165.19(\mathbf{C}=\mathrm{N}, \mathbf{C}=\mathrm{O}) .{ }^{19} \mathrm{~F}$ NMR $(377 \mathrm{MHz}$, DMSO- $\left.d_{6}\right): \quad \delta_{\mathrm{F}}=-73.50 \quad\left(\mathrm{~s}, 3 \mathrm{~F}, \mathrm{CF}_{3}\right), \quad(-109.92$ to $-109.84)$, (-109.53 to -109.45$)(2 \mathrm{~m}, 1 \mathrm{~F}, \mathrm{Ar}-\mathbf{F})$. MS (ESI) $m / z=467.10\left[\mathrm{M}^{+}+1\right]$.

4-(2-(4-Fluorobenzylidene) hydrazinecarbonyl)-1-nonylpyridin-1-ium hexafluorophosphate (13) It was obtained as yellow crystals; mp: $69-70{ }^{\circ} \mathrm{C}$. ${ }^{1} \mathrm{H}$ NMR $\left(400 \mathrm{MHz}, \mathrm{DMSO}-d_{6}\right): \delta_{\mathrm{H}}=0.83-0.87\left(\mathrm{~m}, 3 \mathrm{H}, \mathrm{CH}_{3}\right)$, 1.25-1.30 (m, 12H, $\left.6 \times \mathrm{CH}_{2}\right), 1.94-1.99(\mathrm{~m}, 2 \mathrm{H}$, $\mathrm{NCH}_{2} \mathrm{CH}_{2}$ ), $4.69\left(\mathrm{dd}, 2 \mathrm{H}, J=4 \mathrm{~Hz}, 8 \mathrm{~Hz}, \mathrm{NCH}_{2}\right), 7.25$ (dd, $0.5 \mathrm{H}, J=8 \mathrm{~Hz}, 12 \mathrm{~Hz}, \mathrm{Ar}-\mathrm{H}), 7.37$ (dd, $1.5 \mathrm{H}$, $J=8 \mathrm{~Hz}, 12 \mathrm{~Hz}, \mathrm{Ar}-\mathrm{H}), 7.62$ (dd, $0.5 \mathrm{H}, J=4 \mathrm{~Hz}, 8 \mathrm{~Hz}$, Ar-H), 7.89 (dd, 1.5H, J=4 Hz, $8 \mathrm{~Hz}, \mathrm{Ar}-\mathbf{H}), 8.15(\mathrm{~s}$, $0.25 \mathrm{H}, \mathbf{H}-\mathrm{C}=\mathrm{N}), 8.40(\mathrm{~d}, 0.5 \mathrm{H}, J=8 \mathrm{~Hz}, \mathrm{Ar}-\mathbf{H}), 8.51(\mathrm{~s}$, $0.75 \mathrm{H}, \mathrm{H}-\mathrm{C}=\mathrm{N}), 8.54(\mathrm{~d}, 1.5 \mathrm{H}, J=8 \mathrm{~Hz}, \mathrm{Ar}-\mathrm{H}), 9.24(\mathrm{~d}$, $0.5 \mathrm{H}, J=4 \mathrm{~Hz}, \mathrm{Ar}-\mathbf{H}), 9.33(\mathrm{~d}, 1.5 \mathrm{H}, J=8 \mathrm{~Hz}, \mathrm{Ar}-\mathbf{H})$, 12.51 (s, $1 \mathrm{H}, \mathrm{CONH}) .{ }^{13} \mathrm{C}$ NMR (100 MHz, DMSO- $\left.d_{6}\right)$ : $\delta_{\mathrm{C}}=13.92\left(\mathrm{CH}_{3}\right), 22.03,25.36,25.41,28.35,28.52,28.70$, $28.74,30.51,30.64,31.18\left(7 \times \mathrm{CH}_{2}\right), 60.93,61.01\left(\mathrm{NCH}_{2}\right)$, $115.74,115.96,116.18,126.16,127.11,129.34,129.43$, $129.72,129.81,130.21,130.24,145.06,145.68,147.30$, 149.34 (Ar-C), 158.75, 162.28, 164.75, $165.23(\mathbf{C}=\mathrm{N}$, $\mathrm{C}=\mathrm{O}) .{ }^{31} \mathrm{P}$ NMR $\left(162 \mathrm{MHz}, \mathrm{DMSO}-d_{6}\right): \delta_{\mathrm{P}}=-152.98$ to $-135.42\left(\mathrm{~m}, 1 \mathrm{P}, \mathrm{PF}_{6}\right) \cdot{ }^{19} \mathrm{~F}$ NMR (377 MHz, DMSO- $\left.d_{6}\right)$ : $\delta_{\mathrm{F}}=-69.21\left(\mathrm{~d}, 6 \mathrm{~F}, \mathrm{PF}_{6}\right),(-109.94$ to -109.86$),(-109.42$ to -109.34$)(2 \mathrm{~m}, 1 \mathrm{~F}, \mathrm{Ar}-\mathbf{F})$. MS (ES) $m / z=515.20\left[\mathrm{M}^{+}\right]$.
4-(2-(4-Fluorobenzylidene) hydrazinecarbonyl)-1-nonylpyridin-1-ium tetrafluoroborate (14) It was obtained as yellow crystals; mp: $88-90{ }^{\circ} \mathrm{C}$. ${ }^{1} \mathrm{H}$ NMR $(400 \mathrm{MHz}$, DMSO- $\left.d_{6}\right): \delta_{\mathrm{H}}=0.83-0.87\left(\mathrm{~m}, 3 \mathrm{H}, \mathrm{CH}_{3}\right), 1.25-1.30(\mathrm{~m}$, $\left.12 \mathrm{H}, 6 \times \mathrm{CH}_{2}\right), 1.95-1.99\left(\mathrm{~m}, 2 \mathrm{H}, \mathrm{NCH}_{2} \mathrm{CH}_{2}\right), 4.67(\mathrm{t}, 2 \mathrm{H}$, $\left.J=8 \mathrm{~Hz}, \mathrm{NCH}_{2}\right), 7.25$ (dd, $\left.0.5 \mathrm{H}, J=8 \mathrm{~Hz}, 12 \mathrm{~Hz}, \mathrm{Ar}-\mathbf{H}\right)$, $7.35(\mathrm{t}, 1.5 \mathrm{H}, J=8 \mathrm{~Hz}, \mathrm{Ar}-\mathrm{H}), 7.61(\mathrm{dd}, 0.5 \mathrm{H}, J=4 \mathrm{~Hz}$, $8 \mathrm{~Hz}, \mathrm{Ar}-\mathbf{H}), 7.89(\mathrm{dd}, 1.5 \mathrm{H}, J=4 \mathrm{~Hz}, 8 \mathrm{~Hz}, \mathrm{Ar}-\mathbf{H})$, $8.15(\mathrm{~s}, 0.25 \mathrm{H}, \mathbf{H}-\mathrm{C}=\mathrm{N}), 8.40(\mathrm{~d}, 0.5 \mathrm{H}, J=8 \mathrm{~Hz}, \mathrm{Ar}-\mathbf{H})$, $8.51(\mathrm{~s}, 0.75 \mathrm{H}, \mathrm{H}-\mathrm{C}=\mathrm{N}), 8.53(\mathrm{~d}, 1.5 \mathrm{H}, J=4 \mathrm{~Hz}, \mathrm{Ar}-\mathbf{H})$, $9.24(\mathrm{~d}, 0.5 \mathrm{H}, J=8 \mathrm{~Hz}, \mathrm{Ar}-\mathrm{H}), 9.32(\mathrm{~d}, 1.5 \mathrm{H}, J=8 \mathrm{~Hz}$, Ar-H), 12.49 (bs, $1 \mathrm{H}, \mathrm{CONH}) .{ }^{13} \mathrm{C}$ NMR $(100 \mathrm{MHz}$, DMSO- $\left.d_{6}\right): \delta_{\mathrm{C}}=13.92\left(\mathrm{CH}_{3}\right), 22.03,25.36,28.35,28.52$, 28.70, 30.51, 30.64, $31.18\left(7 \times \mathrm{CH}_{2}\right), 60.94,61.02\left(\mathrm{NCH}_{2}\right)$, $115.74,115.97,116.19,126.16,127.11,129.34,129.43$, $129.72,129.81,130.21,145.07,145.68,147.32,149.34$ (Ar-C), 158.75, 162.29, 164.76, 165.24 $(\mathbf{C}=\mathrm{N}, \mathbf{C}=\mathrm{O}) .{ }^{11} \mathrm{~B}$ NMR $\left(128 \mathrm{MHz}, \mathrm{DMSO}-d_{6}\right): \delta_{\mathrm{B}}=-1.31$ to $-1.30(\mathrm{~m}$, $\left.1 \mathrm{~B}, \mathrm{BF}_{4}\right) \cdot{ }^{19} \mathrm{~F}$ NMR $\left(377 \mathrm{MHz}, \mathrm{DMSO}-d_{6}\right): \delta_{\mathrm{F}}=(-109.94$ to -109.86$)$, $(-109.42$ to -109.34$)(2 \mathrm{~m}, 1 \mathrm{~F}, \mathrm{Ar}-\mathbf{F})$; $-148.29,-148.24\left(2 \mathrm{~d}, 4 \mathrm{~F}, \mathrm{BF}_{4}\right)$. MS (ES) $m / z=457.15$ $\left[\mathrm{M}^{+}\right]$.

4-(2-(4-Fluorobenzylidene) hydrazinecarbonyl)-1-nonylpyridin-1-ium trifluoroacetate (15) It was obtained as yellow crystals; mp: $96-98{ }^{\circ} \mathrm{C} .{ }^{1} \mathrm{H}$ NMR $(400 \mathrm{MHz}$, DMSO- $\left.d_{6}\right): \delta_{\mathrm{H}}=0.83-0.87\left(\mathrm{t}, 3 \mathrm{H}, J=4 \mathrm{~Hz}, \mathrm{CH}_{3}\right), 1.25-$ $1.30\left(\mathrm{~m}, 12 \mathrm{H}, 6 \times \mathrm{CH}_{2}\right), 1.94-1.99\left(\mathrm{~m}, 2 \mathrm{H}, \mathrm{NCH}_{2} \mathrm{CH}_{2}\right)$, $4.68\left(\mathrm{t}, 2 \mathrm{H}, J=8 \mathrm{~Hz}, \mathrm{NCH}_{2}\right), 7.25(\mathrm{dd}, 0.5 \mathrm{H}, J=8 \mathrm{~Hz}$, $12 \mathrm{~Hz}, \mathrm{Ar}-\mathbf{H}), 7.37$ (dd, $1.5 \mathrm{H}, J=8 \mathrm{~Hz}, 12 \mathrm{~Hz}, \mathrm{Ar}-\mathbf{H})$, $7.62(\mathrm{dd}, 0.5 \mathrm{H}, J=4 \mathrm{~Hz}, 8 \mathrm{~Hz}, \mathrm{Ar}-\mathbf{H}), 7.88(\mathrm{dd}, 1.5 \mathrm{H}$, $J=4 \mathrm{~Hz}, 8 \mathrm{~Hz}, \mathrm{Ar}-\mathbf{H}), 8.16(\mathrm{~s}, 0.25 \mathrm{H}, \mathrm{H}-\mathrm{C}=\mathrm{N}), 8.40(\mathrm{~d}$, $0.5 \mathrm{H}, J=8 \mathrm{~Hz}, \mathrm{Ar}-\mathbf{H}), 8.51(\mathrm{~s}, 0.75 \mathrm{H}, \mathbf{H}-\mathrm{C}=\mathrm{N}), 8.53(\mathrm{~d}$, $1.5 \mathrm{H}, J=4 \mathrm{~Hz}, \mathrm{Ar}-\mathbf{H}), 9.25(\mathrm{~d}, 0.5 \mathrm{H}, J=8 \mathrm{~Hz}, \mathrm{Ar}-\mathbf{H}), 9.33$ (d, $1.5 \mathrm{H}, J=4 \mathrm{~Hz}, \mathrm{Ar}-\mathrm{H}), 12.50$ (s, 0.75H, CONH), 12.51 (s, 0.25H, CONH). ${ }^{13} \mathrm{C}$ NMR (100 MHz, DMSO- $\left.d_{6}\right)$ : $\delta_{\mathrm{C}}=13.91\left(\mathrm{CH}_{3}\right), 22.03,25.36,28.34,25.41,28.34,28.52$, 28.70, 28.73, 30.51, 30.64, $31.18\left(7 \times \mathrm{CH}_{2}\right), 60.93,61.00$ $\left(\mathrm{NCH}_{2}\right), 115.74,115.96,116.18,126.15,127.11,129.34$, $129.43,129.80,130.04,130.21,130.24,145.07,145.69$, 147.31, 149.35, 149.65 (Ar-C), 158.75, 162.28, 164.75, $165.23(\mathbf{C}=\mathrm{N}, \mathbf{C}=\mathrm{O}) .{ }^{19} \mathrm{~F}$ NMR (377 MHz, DMSO- $\left.d_{6}\right)$ : $\delta_{\mathrm{F}}=-73.50$ (s, 3F, CF $\left.\mathbf{C}_{3}\right),(-109.96$ to -109.88$),(-109.44$ to -109.36$)(2 \mathrm{~m}, 1 \mathrm{~F}, \mathrm{Ar}-\mathrm{F})$. MS (ES) $m / z=483.20\left[\mathrm{M}^{+}\right]$.

1-Decyl-4-(2-(4-fluorobenzylidene) hydrazinecarbonyl)pyridin-1-ium hexafluorophosphate (16) It was obtained as yellow syrup. ${ }^{1} \mathrm{H}$ NMR (400 MHz, DMSO$\left.d_{6}\right): \delta_{\mathrm{H}}=0.83-0.88\left(\mathrm{~m}, 3 \mathrm{H}, \mathrm{CH}_{3}\right), 1.25-1.30(\mathrm{~m}, 14 \mathrm{H}$, $\left.7 \times \mathrm{CH}_{2}\right), \quad 1.95-1.98\left(\mathrm{~m}, 2 \mathrm{H}, \mathrm{NCH}_{2} \mathrm{CH}_{2}\right), 4.67(\mathrm{t}, 2 \mathrm{H}$, $\left.J=8 \mathrm{~Hz}, \mathrm{NCH}_{2}\right), 7.25(\mathrm{dd}, 0.5 \mathrm{H}, J=8 \mathrm{~Hz}, 12 \mathrm{~Hz}, \mathrm{Ar}-\mathbf{H})$, $7.35(\mathrm{t}, 1.5 \mathrm{H}, J=8 \mathrm{~Hz}, \mathrm{Ar}-\mathrm{H}), 7.62(\mathrm{dd}, 0.5 \mathrm{H}, J=4 \mathrm{~Hz}$, $8 \mathrm{~Hz}, \mathrm{Ar}-\mathbf{H}), 7.89(\mathrm{dd}, 1.5 \mathrm{H}, J=4 \mathrm{~Hz}, 8 \mathrm{~Hz}, \mathrm{Ar}-\mathbf{H}), 8.16$ 
(s, $0.25 \mathrm{H}, \mathbf{H}-\mathrm{C}=\mathrm{N}), 8.40(\mathrm{~d}, 0.5 \mathrm{H}, J=8 \mathrm{~Hz}, \mathrm{Ar}-\mathbf{H}), 8.50$ $(\mathrm{s}, 0.75 \mathrm{H}, \mathrm{H}-\mathrm{C}=\mathrm{N}), 8.53(\mathrm{~d}, 1.5 \mathrm{H}, J=4 \mathrm{~Hz}, \mathrm{Ar}-\mathrm{H}), 9.23$ (d, $0.5 \mathrm{H}, J=4 \mathrm{~Hz}, \mathrm{Ar}-\mathrm{H}), 9.31$ (d, $1.5 \mathrm{H}, J=8 \mathrm{~Hz}, \mathrm{Ar}-\mathbf{H}$ ), 12.48 (bs, $1 \mathrm{H}, \mathrm{CONH}) .{ }^{13} \mathrm{C}$ NMR $\left(100 \mathrm{MHz}, \mathrm{DMSO}-d_{6}\right)$ : $\delta_{\mathrm{C}}=13.90\left(\mathrm{CH}_{3}\right), 22.04,25.36,25.40,28.33,28.60,28.74$, 28.77, 28.82, 30.50, 30.63, $31.23\left(8 \times \mathrm{CH}_{2}\right), 60.96,61.06$ $\left(\mathrm{NCH}_{2}\right), 115.72,115.95,116.16,126.15,127.12,129.32$, $129.41,129.72,129.81,130.07,130.21,130.24,145.05$, 145.67, 147.34, 149.36, 149.67, (Ar-C), 158.75, 162.28, 164.77, $165.22(\mathbf{C}=\mathrm{N}, \mathbf{C}=\mathrm{O}) .{ }^{31} \mathrm{P}$ NMR $(162 \mathrm{MHz}$, DMSO- $\left.d_{6}\right): \delta_{\mathrm{P}}=-157.37$ to $-131.02\left(\mathrm{~m}, 1 \mathrm{P}, \mathrm{PF}_{6}\right) .{ }^{19} \mathrm{~F}$ NMR $\left(377 \mathrm{MHz}\right.$, DMSO- $\left.d_{6}\right): \delta_{\mathrm{F}}=-69.22\left(\mathrm{~d}, 6 \mathrm{~F}, \mathrm{PF}_{6}\right)$, ( -109.94 to -109.85$)$, $(-109.42$ to -109.34$)(2 \mathrm{~m}, 1 \mathrm{~F}$, $\mathrm{Ar}-\mathbf{F})$. MS (ES) $m / z=529.70\left[\mathrm{M}^{+}\right]$.

1-Decyl-4-(2-(4-fluorobenzylidene) hydrazinecarbonyl) pyridin-1-ium tetrafluoroborate (17) It was obtained as colorless syrup. ${ }^{1} \mathrm{H}$ NMR $\left(400 \mathrm{MHz}\right.$, DMSO- $\left.d_{6}\right)$ : $\delta_{\mathrm{H}}=0.83-0.87 \quad\left(\mathrm{~m}, 3 \mathrm{H}, \mathrm{CH}_{3}\right), 1.25-1.30 \quad(\mathrm{~m}, 14 \mathrm{H}$, $\left.7 \times \mathrm{CH}_{2}\right), 1.95-1.98\left(\mathrm{~m}, 2 \mathrm{H}, \mathrm{NCH}_{2} \mathrm{CH}_{2}\right), 4.67(\mathrm{t}, 2 \mathrm{H}$, $\left.J=8 \mathrm{~Hz}, \mathrm{NCH}_{2}\right), 7.25(\mathrm{dd}, 0.5 \mathrm{H}, J=8 \mathrm{~Hz}, 12 \mathrm{~Hz}, \mathrm{Ar}-\mathbf{H})$, $7.35(\mathrm{t}, 1.5 \mathrm{H}, J=8 \mathrm{~Hz}, \mathrm{Ar}-\mathrm{H}), 7.62(\mathrm{dd}, 0.5 \mathrm{H}, J=8 \mathrm{~Hz}$, $12 \mathrm{~Hz}, \mathrm{Ar}-\mathbf{H}), 7.89$ (dd, $1.5 \mathrm{H}, J=4 \mathrm{~Hz}, 8 \mathrm{~Hz}, \mathrm{Ar}-\mathbf{H}), 8.16$ $(\mathrm{s}, 0.25 \mathrm{H}, \mathbf{H}-\mathrm{C}=\mathrm{N}), 8.40(\mathrm{~d}, 0.5 \mathrm{H}, J=8 \mathrm{~Hz}, \mathrm{Ar}-\mathbf{H}), 8.52$ $(\mathrm{s}, 0.75 \mathrm{H}, \mathrm{H}-\mathrm{C}=\mathrm{N}), 8.55(\mathrm{~d}, 1.5 \mathrm{H}, J=8 \mathrm{~Hz}, \mathrm{Ar}-\mathrm{H}), 9.24$ (d, $0.5 \mathrm{H}, J=4 \mathrm{~Hz}, \mathrm{Ar}-\mathrm{H}), 9.32$ (d, $1.5 \mathrm{H}, J=4 \mathrm{~Hz}, \mathrm{Ar}-\mathrm{H})$, 12.52 (bs, $1 \mathrm{H}, \mathrm{CONH}) .{ }^{13} \mathrm{C}$ NMR $\left(100 \mathrm{MHz}, \mathrm{DMSO}-d_{6}\right)$ : $\delta_{\mathrm{C}}=13.90,13.91\left(\mathrm{CH}_{3}\right), 22.05,25.36,25.40,28.34,28.61$, 28.75, 28.78, 28.83, 30.50, 30.63, 31.23, $\left(8 \times \mathrm{CH}_{2}\right), 60.94$, $61.01\left(\mathrm{NCH}_{2}\right), 115.74,115.96,116.18,126.16,127.11$, $129.34,129.42,129.71,129.80,130.07,130.23,130.26$, 145.07, 145.67, 147.34, 149.35 (Ar-C), 158.76, 162.28, 164.75, 165.23, $(\mathbf{C}=\mathrm{N}, \mathbf{C}=\mathrm{O}) .{ }^{11} \mathrm{~B}$ NMR $(128 \mathrm{MHz}$, DMSO- $\left.d_{6}\right): \delta_{\mathrm{B}}=-1.31$ to $-1.29\left(\mathrm{~m}, 1 \mathrm{~B}, \mathrm{BF}_{4}\right) \cdot{ }^{19} \mathrm{~F}$ NMR (377 MHz, DMSO- $\left.d_{6}\right)$ : $\delta_{\mathrm{F}}=(-109.94$ to -109.88$)$, $(-109.44$ to -109.36$)(2 \mathrm{~m}, 1 \mathrm{~F}, \mathrm{Ar}-\mathrm{F}) ;-148.30,-148.24$ $\left(2 \mathrm{~d}, 4 \mathrm{~F}, \mathrm{BF}_{4}\right)$. MS (ES) $m / z=471.60\left[\mathrm{M}^{+}\right]$.

1-Decyl-4-(2-(4-fluorobenzylidene) hydrazinecarbonyl) pyridin-1-ium trifluoroacetate (18) It was obtained as yellow syrup. ${ }^{1} \mathrm{H}$ NMR $\left(400 \mathrm{MHz}\right.$, DMSO- $\left.d_{6}\right)$ : $\delta_{\mathrm{H}}=0.83-$ $0.87\left(\mathrm{~m}, 3 \mathrm{H}, \mathrm{CH}_{3}\right), 1.25-1.30\left(\mathrm{~m}, 14 \mathrm{H}, 7 \times \mathrm{CH}_{2}\right), 1.95-$ $1.98\left(\mathrm{~m}, 2 \mathrm{H}, \mathrm{NCH}_{2} \mathrm{CH}_{2}\right), 4.68\left(\mathrm{t}, 2 \mathrm{H}, J=8 \mathrm{~Hz}, \mathrm{NCH}_{2}\right)$, 7.25 (dd, $0.5 \mathrm{H}, J=8 \mathrm{~Hz}, 12 \mathrm{~Hz}, \mathrm{Ar}-\mathbf{H}), 7.37$ (dd, $1.5 \mathrm{H}$, $J=8 \mathrm{~Hz}, 12 \mathrm{~Hz}, A r-\mathbf{H}), 7.62(\mathrm{dd}, 0.5 \mathrm{H}, J=4 \mathrm{~Hz}, 8 \mathrm{~Hz}$, Ar-H), 7.88 (dd, $1.5 \mathrm{H}, J=4 \mathrm{~Hz}, 8 \mathrm{~Hz}, \mathrm{Ar}-\mathbf{H}), 8.17$ (s, $0.25 \mathrm{H}, \mathbf{H}-\mathrm{C}=\mathrm{N}), 8.40(\mathrm{~d}, 0.5 \mathrm{H}, J=8 \mathrm{~Hz}, \mathrm{Ar}-\mathbf{H}), 8.52(\mathrm{~s}$, $0.75 \mathrm{H}, \mathbf{H}-\mathrm{C}=\mathrm{N}), 8.55(\mathrm{~d}, 1.5 \mathrm{H}, J=8 \mathrm{~Hz}, \mathrm{Ar}-\mathbf{H}), 9.25(\mathrm{~d}$, $0.5 \mathrm{H}, J=4 \mathrm{~Hz}, \mathrm{Ar}-\mathbf{H}), 9.33(\mathrm{~d}, 1.5 \mathrm{H}, J=8 \mathrm{~Hz}, \mathrm{Ar}-\mathbf{H})$, 12.56 (bs, $1 \mathrm{H}, \mathrm{CONH}) .{ }^{13} \mathrm{C}$ NMR $\left(100 \mathrm{MHz}, \mathrm{DMSO}-d_{6}\right)$ : $\delta_{\mathrm{C}}=13.89,13.91\left(\mathrm{CH}_{3}\right), 22.05,25.36,25.40,28.34,28.61$, 28.74, 28.78, 28.82, 30.50, 30.64, $31.23\left(8 \times \mathrm{CH}_{2}\right), 60.94$, $60.98\left(\mathrm{NCH}_{2}\right), 115.74,115.95,116.16,126.13,127.11$,
129.33, 129.42, 129.69, 129.77, 130.07, 130.28, 130.31, 145.07, 145.65, 147.48, 149.35 (Ar-C), 158.82, 162.25, 164.73, $165.23(\mathbf{C}=\mathrm{N}, \mathbf{C}=\mathrm{O}) .{ }^{19} \mathrm{~F}$ NMR $(377 \mathrm{MHz}$, DMSO- $\left.d_{6}\right): \delta_{\mathrm{F}}=-73.52 \quad\left(\mathrm{~s}, \quad 3 \mathrm{~F}, \quad \mathrm{CF}_{3}\right), \quad(-109.95$ to $-109.87),(-109.50$ to -109.42$)$ (2m, 1F, Ar-F). MS (ES) $m / z=497.33\left[\mathrm{M}^{+}\right]$.

4-(2-(4-Fluorobenzylidene)hydrazinecarbonyl)-1-undecylpyridin-1-ium hexafluorophosphate (19) It was obtained as yellow syrup. ${ }^{1} \mathrm{H}$ NMR $(400 \mathrm{MHz}, \mathrm{DMSO}-$ $\left.d_{6}\right): \delta_{\mathrm{H}}=0.83-0.87\left(\mathrm{~m}, 3 \mathrm{H}, \mathrm{CH}_{3}\right), 1.24-1.30(\mathrm{~m}, 16 \mathrm{H}$, $\left.8 \times \mathrm{CH}_{2}\right), 1.96-1.99\left(\mathrm{~m}, 2 \mathrm{H}, \mathrm{NCH}_{2} \mathrm{CH}_{2}\right), 4.69(\mathrm{dd}, 2 \mathrm{H}$, $\left.J=4 \mathrm{~Hz}, 8 \mathrm{~Hz}, \mathrm{NCH}_{2}\right), 7.22(\mathrm{t}, 0.5 \mathrm{H}, J=8 \mathrm{~Hz}, \mathrm{Ar}-\mathbf{H})$, 7.36 (dd, $1.5 \mathrm{H}, J=4 \mathrm{~Hz}, 8 \mathrm{~Hz}, \mathrm{Ar}-\mathbf{H}), 7.61(\mathrm{dd}, 0.5 \mathrm{H}$, $J=4 \mathrm{~Hz}, 8 \mathrm{~Hz}, \mathrm{Ar}-\mathrm{H}), 7.88(\mathrm{dd}, 1.5 \mathrm{H}, J=4 \mathrm{~Hz}, 8 \mathrm{~Hz}$, $\mathrm{Ar}-\mathrm{H}), 8.16(\mathrm{~s}, 0.25 \mathrm{H}, \mathrm{H}-\mathrm{C}=\mathrm{N}), 8.39(\mathrm{~d}, 0.5 \mathrm{H}, J=4 \mathrm{~Hz}$, $\mathrm{Ar}-\mathrm{H}), 8.53(\mathrm{~s}, 0.75 \mathrm{H}, \mathrm{H}-\mathrm{C}=\mathrm{N}), 8.54(\mathrm{~d}, 1.5 \mathrm{H}, J=4 \mathrm{~Hz}$, $\operatorname{Ar}-\mathbf{H}), 9.24(\mathrm{~d}, 0.5 \mathrm{H}, J=4 \mathrm{~Hz}, \operatorname{Ar}-\mathbf{H}), 9.33(\mathrm{~d}, 1.5 \mathrm{H}$, $J=8 \mathrm{~Hz}, \mathrm{Ar}-\mathrm{H}$ ), 12.51 (bs, $1 \mathrm{H}, \mathrm{CONH}) .{ }^{13} \mathrm{C}$ NMR $\left(100 \mathrm{MHz}, \mathrm{DMSO}-d_{6}\right): \delta_{\mathrm{C}}=13.90\left(\mathrm{CH}_{3}\right), 22.04,25.36$, $28.34,28.64,28.74,28.87,28.91,30.49,30.63,31.24$ $\left(9 \times \mathrm{CH}_{2}\right), 60.95,61.03\left(\mathrm{NCH}_{2}\right), 115.73,115.95,116.17$, $126.16,127.11,129.34,129.42,129.71,128.80,130.07$, 130.26, 145.08, 145.67, 147.32, 149.38, $149.66(\mathrm{Ar}-\mathrm{C})$, $158.73,162.28,164.76,165.20(\mathbf{C}=\mathrm{N}, \mathbf{C}=\mathrm{O}) .{ }^{31} \mathrm{P}$ NMR $\left(162 \mathrm{MHz}, \mathrm{DMSO}-d_{6}\right): \delta_{\mathrm{P}}=-152.97$ to $-135.41(\mathrm{~m}, 1 \mathrm{P}$, PF $\left._{6}\right) .{ }^{19} \mathrm{~F}$ NMR $\left(377 \mathrm{MHz}, \mathrm{DMSO}-d_{6}\right): \delta_{\mathrm{F}}=-69.24(\mathrm{~d}, 6 \mathrm{~F}$, $\left.\mathrm{PF}_{6}\right),(-109.95$ to -109.88$),(-109.35$ to -109.37$)$ (2m, $1 \mathrm{~F}, \mathrm{Ar}-\mathbf{F})$. MS (ES) $m / z=543.40\left[\mathrm{M}^{+}\right]$.

4-(2-(4-Fluorobenzylidene)hydrazinecarbonyl)-1-undecylpyridin-1-ium tetrafluoroborate (20) It was obtained as yellow syrup. ${ }^{1} \mathrm{H}$ NMR $(400 \mathrm{MHz}$, DMSO$\left.d_{6}\right): \delta_{\mathrm{H}}=0.83-0.87\left(\mathrm{~m}, 3 \mathrm{H}, \mathrm{CH}_{3}\right), 1.24-1.30(\mathrm{~m}, 16 \mathrm{H}$, $\left.8 \times \mathrm{CH}_{2}\right), 1.96-1.99\left(\mathrm{~m}, 2 \mathrm{H}, \mathrm{NCH}_{2} \mathrm{CH}_{2}\right), 4.68(\mathrm{t}, 2 \mathrm{H}$, $\left.J=8 \mathrm{~Hz}, \mathrm{NCH}_{2}\right), 7.22(\mathrm{t}, 0.5 \mathrm{H}, J=8 \mathrm{~Hz}, \mathrm{Ar}-\mathrm{H}), 7.34(\mathrm{t}$, $1.5 \mathrm{H}, J=8 \mathrm{~Hz}, \mathrm{Ar}-\mathrm{H}), 7.61(\mathrm{dd}, 0.5 \mathrm{H}, J=4 \mathrm{~Hz}, 8 \mathrm{~Hz}$, Ar-H), 7.88 (dd, $1.5 \mathrm{H}, J=4 \mathrm{~Hz}, 8 \mathrm{~Hz}, \mathrm{Ar}-\mathbf{H}), 8.17$ (s, $0.25 \mathrm{H}, \mathbf{H}-\mathrm{C}=\mathrm{N}), 8.39(\mathrm{~d}, 0.5 \mathrm{H}, J=4 \mathrm{~Hz}, \mathrm{Ar}-\mathrm{H}), 8.56(\mathrm{~s}$, $0.75 \mathrm{H}, \mathbf{H}-\mathrm{C}=\mathrm{N}), 8.58(\mathrm{~d}, 1.5 \mathrm{H}, J=8 \mathrm{~Hz}, \mathrm{Ar}-\mathbf{H}), 9.25(\mathrm{~d}$, $0.5 \mathrm{H}, J=4 \mathrm{~Hz}, \mathrm{Ar}-\mathbf{H}), 9.34(\mathrm{~d}, 1.5 \mathrm{H}, J=8 \mathrm{~Hz}, \mathrm{Ar}-\mathbf{H})$, 12.52 (s, $0.25 \mathrm{H}, \mathrm{CONH}), 12.64(\mathrm{~s}, 0.75 \mathrm{H}, \mathrm{CONH}) .{ }^{13} \mathrm{C}$ NMR $\left(100 \mathrm{MHz}\right.$, DMSO- $\left.d_{6}\right): \delta_{\mathrm{C}}=13.89\left(\mathrm{CH}_{3}\right), 22.03$, 25.36, 28.34, 28.64, 28.73, 28.87, 28.91, 30.49, 30.63, 31.24 $\left(9 \times \mathrm{CH}_{2}\right), 60.95,61.01\left(\mathrm{NCH}_{2}\right), 115.73,115.94,116.16$, $126.19,127.10,129.34,129.43,129.69,129.78,130.07$, $130.25,130.28,145.08,145.66,147.25,149.40,149.66$ (Ar-C), 158.70, 162.27, 164.74, $165.19(\mathbf{C}=\mathrm{N}, \mathrm{C}=\mathrm{O}) .{ }^{11} \mathrm{~B}$ NMR $\left(128 \mathrm{MHz}\right.$, DMSO- $\left.d_{6}\right): \delta_{\mathrm{B}}=-1.30$ to $-1.28(\mathrm{~m}$, 1B, $\left.\mathbf{B F}_{4}\right) \cdot{ }^{19} \mathrm{~F}$ NMR $\left(377 \mathrm{MHz}, \mathrm{DMSO}-d_{6}\right): \delta_{\mathrm{F}}=(-109.97$ to -109.89$),(-109.48$ to -109.40$)(2 \mathrm{~m}, 1 \mathrm{~F}, \mathrm{Ar}-\mathrm{F})$; $-148.36,-148.30\left(2 \mathrm{~d}, 4 \mathrm{~F}, \mathrm{BF}_{4}\right.$ ). MS (ES) $m / z=485.20$ $\left[\mathrm{M}^{+}\right]$. 
4-(2-(4-Fluorobenzylidene)hydrazinecarbonyl)-1-undecylpyridin-1-ium trifluoroacetate (21) It was obtained as colorless syrup. ${ }^{1} \mathrm{H}$ NMR $\left(400 \mathrm{MHz}\right.$, DMSO- $\left.d_{6}\right)$ : $\delta_{\mathrm{H}}=0.83-0.87 \quad\left(\mathrm{~m}, 3 \mathrm{H}, \mathrm{CH}_{3}\right), 1.24-1.30 \quad(\mathrm{~m}, 16 \mathrm{H}$, $\left.8 \times \mathrm{CH}_{2}\right), 1.96-1.99\left(\mathrm{~m}, 2 \mathrm{H}, \mathrm{NCH}_{2} \mathrm{CH}_{2}\right), 4.69(\mathrm{dd}, 2 \mathrm{H}$, $\left.J=4 \mathrm{~Hz}, 8 \mathrm{~Hz}, \mathrm{NCH}_{2}\right), 7.22(\mathrm{t}, 0.5 \mathrm{H}, J=8 \mathrm{~Hz}, \mathrm{Ar}-\mathbf{H}), 7.36$ $(\mathrm{dd}, 1.5 \mathrm{H}, J=8 \mathrm{~Hz}, 12 \mathrm{~Hz}, \mathrm{Ar}-\mathrm{H}), 7.61$ (dd, $0.5 \mathrm{H}, J=4 \mathrm{~Hz}$, $8 \mathrm{~Hz}, \mathrm{Ar}-\mathbf{H}), 7.87(\mathrm{dd}, 1.5 \mathrm{H}, J=4 \mathrm{~Hz}, 8 \mathrm{~Hz}, \mathrm{Ar}-\mathbf{H}), 8.16$ $(\mathrm{s}, 0.25 \mathrm{H}, \mathrm{H}-\mathrm{C}=\mathrm{N}), 8.39(\mathrm{~d}, 0.5 \mathrm{H}, J=4 \mathrm{~Hz}, \mathrm{Ar}-\mathbf{H}), 8.51$ $(\mathrm{s}, 0.75 \mathrm{H}, \mathrm{H}-\mathrm{C}=\mathrm{N}), 8.54(\mathrm{~d}, 1.5 \mathrm{H}, J=8 \mathrm{~Hz}, \mathrm{Ar}-\mathbf{H}), 9.25$ (d, $0.5 \mathrm{H}, J=8 \mathrm{~Hz}, \mathrm{Ar}-\mathrm{H}), 9.32(\mathrm{~d}, 1.5 \mathrm{H}, J=4 \mathrm{~Hz}, \mathrm{Ar}-\mathbf{H})$, 12.54 (bs, $1 \mathrm{H}, \mathrm{CONH}) .{ }^{13} \mathrm{C}$ NMR $\left(100 \mathrm{MHz}, \mathrm{DMSO}-d_{6}\right)$ : $\delta_{\mathrm{C}}=13.89\left(\mathrm{CH}_{3}\right), 22.03,25.36,28.33,28.64,28.73,28.87$, $28.91,30.49,30.63,31.24\left(9 \times \mathrm{CH}_{2}\right), 60.96,60.99\left(\mathrm{NCH}_{2}\right)$, $115.73,115.93,116.15,126.12,127.11,129.34,129.42$, $129.67,129.76,130.05,130.30,130.33,145.07,145.63$, 147.55, 149.38, 149.67 (Ar-C), 158.82, 162.25, 164.72, $165.20(\mathbf{C}=\mathrm{N}, \mathbf{C}=\mathrm{O}) .{ }^{19} \mathrm{~F}$ NMR (377 MHz, DMSO- $\left.d_{6}\right)$ : $\delta_{\mathrm{F}}=-73.53$ (s, 3F, CF $\left.)_{3}\right),(-109.97$ to -109.89$),(-109.54$ to -109.46$)(2 \mathrm{~m}, 1 \mathrm{~F}, \mathrm{Ar}-\mathbf{F})$. MS (ES) $m / z=511.30\left[\mathrm{M}^{+}\right]$.

1-Dodecyl-4-(2-(4-fluorobenzylidene) hydrazinecarbonyl)pyridin-1-ium hexafluorophosphate (22) It was obtained as yellow syrup. ${ }^{1} \mathrm{H}$ NMR $(400 \mathrm{MHz}$, DMSO$\left.d_{6}\right): \delta_{\mathrm{H}}=0.83-0.87\left(\mathrm{~m}, 3 \mathrm{H}, \mathrm{CH}_{3}\right), 1.24-1.30(\mathrm{~m}, 18 \mathrm{H}$, $\left.9 \times \mathrm{CH}_{2}\right), 1.96-1.98\left(\mathrm{~m}, 2 \mathrm{H}, \mathrm{NCH}_{2} \mathrm{CH}_{2}\right), 4.69(\mathrm{dd}, 2 \mathrm{H}$, $\left.J=4 \mathrm{~Hz}, 8 \mathrm{~Hz}, \mathrm{NCH}_{2}\right), 7.22(\mathrm{t}, 0.5 \mathrm{H}, J=8 \mathrm{~Hz}, \mathrm{Ar}-\mathbf{H})$, $7.37(\mathrm{dd}, 1.5 \mathrm{H}, J=8 \mathrm{~Hz}, 12 \mathrm{~Hz}, \mathrm{Ar}-\mathrm{H}), 7.61(\mathrm{dd}, 0.5 \mathrm{H}$, $J=4 \mathrm{~Hz}, 8 \mathrm{~Hz}, \mathrm{Ar}-\mathrm{H}), 7.89$ (dd, $1.5 \mathrm{H}, J=4 \mathrm{~Hz}, 8 \mathrm{~Hz}$, $\mathrm{Ar}-\mathrm{H}), 8.16(\mathrm{~s}, 0.25 \mathrm{H}, \mathrm{H}-\mathrm{C}=\mathrm{N}), 8.39(\mathrm{~d}, 0.5 \mathrm{H}, J=4 \mathrm{~Hz}$, $\mathrm{Ar}-\mathbf{H}), 8.51(\mathrm{~s}, 0.75 \mathrm{H}, \mathbf{H}-\mathrm{C}=\mathrm{N}), 8.53(\mathrm{~d}, 1.5 \mathrm{H}, J=4 \mathrm{~Hz}$, $\operatorname{Ar}-\mathbf{H}), 9.24(\mathrm{~d}, 0.5 \mathrm{H}, J=4 \mathrm{~Hz}, \mathrm{Ar}-\mathrm{H}), 9.33(\mathrm{~d}, 1.5 \mathrm{H}$, $J=8 \mathrm{~Hz}, \mathrm{Ar}-\mathrm{H}$ ), 12.47 (bs, $1 \mathrm{H}, \mathrm{CONH}) .{ }^{13} \mathrm{C}$ NMR $\left(100 \mathrm{MHz}, \mathrm{DMSO}-d_{6}\right): \delta_{\mathrm{C}}=13.89\left(\mathrm{CH}_{3}\right), 22.03,25.36$, $28.33,28.65,28.73,28.86,28.95,30.48,30.62,31.24$ $\left(10 \times \mathrm{CH}_{2}\right), 60.96,61.03\left(\mathrm{NCH}_{2}\right), 115.73,115.95,116.17$, $126.14,127.11,129.34,129.43,129.72,129.81,130.04$, 130.25, 145.09, 145.68, 147.34, 149.38, 149.66 (Ar-C), $158.74,162.29,164.76,165.20(\mathbf{C}=\mathrm{N}, \mathbf{C}=\mathrm{O}) .{ }^{31} \mathrm{P}$ NMR $\left(162 \mathrm{MHz}, \mathrm{DMSO}-d_{6}\right)$ : $\delta_{\mathrm{P}}=-157.37$ to $-131.02(\mathrm{~m}, 1 \mathrm{P}$, $\left.\mathrm{PF}_{6}\right) \cdot{ }^{19} \mathrm{~F}$ NMR $\left(377 \mathrm{MHz}, \mathrm{DMSO}-d_{6}\right): \delta_{\mathrm{F}}=-69.25(\mathrm{~d}, 6 \mathrm{~F}$, $\left.\mathrm{PF}_{6}\right),(-109.95$ to -109.88$),(-109.44$ to -109.36$)$ ( $2 \mathrm{~m}$, 1F, Ar-F). MS (ES) $m / z=557.30\left[\mathrm{M}^{+}\right]$.

\section{1-Dodecyl-4-(2-(4-fluorobenzylidene)}

hydrazinecarbonyl)pyridin-1-ium tetrafluoroborate (23) It was obtained as yellow syrup. ${ }^{1} \mathrm{H}$ NMR (400 MHz, DMSO$\left.d_{6}\right): \delta_{\mathrm{H}}=0.83\left(\mathrm{t}, 3 \mathrm{H}, J=8 \mathrm{~Hz}, \mathrm{CH}_{3}\right), 1.24-1.30(\mathrm{~m}, 18 \mathrm{H}$, $\left.9 \times \mathrm{CH}_{2}\right), 1.96-1.98\left(\mathrm{~m}, 2 \mathrm{H}, \mathrm{NCH}_{2} \mathrm{CH}_{2}\right), 4.68(\mathrm{t}, 2 \mathrm{H}$, $\left.J=8 \mathrm{~Hz}, \mathrm{NCH}_{2}\right), 7.22(\mathrm{t}, 0.5 \mathrm{H}, J=8 \mathrm{~Hz}, \mathrm{Ar}-\mathbf{H}), 7.34(\mathrm{t}$, $1.5 \mathrm{H}, J=8 \mathrm{~Hz}, \mathrm{Ar}-\mathrm{H}), 7.62(\mathrm{dd}, 0.5 \mathrm{H}, J=4 \mathrm{~Hz}, 8 \mathrm{~Hz}$, Ar-H), 7.88 (dd, $1.5 \mathrm{H}, J=4 \mathrm{~Hz}, 8 \mathrm{~Hz}, \mathrm{Ar}-\mathrm{H}), 8.16(\mathrm{~s}$, $0.25 \mathrm{H}, \mathrm{H}-\mathrm{C}=\mathrm{N}), 8.39(\mathrm{~d}, 0.5 \mathrm{H}, J=4 \mathrm{~Hz}, \mathrm{Ar}-\mathrm{H}), 8.52(\mathrm{~s}$,
$0.75 \mathrm{H}, \mathrm{H}-\mathrm{C}=\mathrm{N}), 8.54(\mathrm{~d}, 1.5 \mathrm{H}, J=8 \mathrm{~Hz}, \mathrm{Ar}-\mathrm{H}), 9.25(\mathrm{~d}$, $0.5 \mathrm{H}, J=8 \mathrm{~Hz}, \mathrm{Ar}-\mathbf{H}), 9.33$ (d, $1.5 \mathrm{H}, J=4 \mathrm{~Hz}, \mathrm{Ar}-\mathbf{H})$, 12.48 (bs, $1 \mathrm{H}, \mathrm{CONH}) .{ }^{13} \mathrm{C}$ NMR $(100 \mathrm{MHz}, \mathrm{DMSO}-$ $\left.d_{6}\right): \delta_{\mathrm{C}}=13.89\left(\mathrm{CH}_{3}\right), 22.03,25.36,28.33,28.65,28.74$, 28.86, 28.95, 30.48, 30.62, 31.24 $\left(10 \times \mathrm{CH}_{2}\right), 60.96,61.03$ $\left(\mathrm{NCH}_{2}\right), 115.73,115.94,116.16,126.15,127.11,129.34$, $129.43,129.72,129.80,130.22,130.25,145.08,145.69$, 147.32, 149.38, 149.66 (Ar-C), 158.73, 162.29, 164.76, $165.19(\mathbf{C}=\mathrm{N}, \mathbf{C}=\mathrm{O}) .{ }^{11} \mathrm{~B}$ NMR (128 MHz, DMSO- $\left.d_{6}\right)$ : $\delta_{\mathrm{B}}=-1.31$ to $-1.28\left(\mathrm{~m}, 1 \mathrm{~B}, \mathrm{BF}_{4}\right) .{ }^{19} \mathrm{~F}$ NMR $(377 \mathrm{MHz}$, DMSO- $\left.d_{6}\right): \delta_{\mathrm{F}}=(-109.96$ to -109.88$),(-109.45$ to -109.37) (2m, 1F, Ar-F); - 148.36, - 148.30 (2d, 4F, $\left.\mathrm{BF}_{4}\right)$. MS (ES) $m / z=499.20\left[\mathrm{M}^{+}\right]$.

1-Dodecyl-4-(2-(4-fluorobenzylidene) hydrazinecarbonyl) pyridin-1-ium trifluoroacetate (24) It was obtained as colorless syrup. ${ }^{1} \mathrm{H}$ NMR $\left(400 \mathrm{MHz}\right.$, DMSO- $\left.d_{6}\right)$ : $\delta_{\mathrm{H}}=0.85\left(\mathrm{t}, 3 \mathrm{H}, J=8 \mathrm{~Hz}, \mathrm{CH}_{3}\right), 1.24-1.30(\mathrm{~m}, 18 \mathrm{H}$, $\left.9 \times \mathrm{CH}_{2}\right), 1.96-1.98\left(\mathrm{~m}, 2 \mathrm{H}, \mathrm{NCH}_{2} \mathrm{CH}_{2}\right), 4.68(\mathrm{t}, 2 \mathrm{H}$, $\left.J=8 \mathrm{~Hz}, \mathrm{NCH}_{2}\right), 7.22(\mathrm{t}, 0.5 \mathrm{H}, J=8 \mathrm{~Hz}, \mathrm{Ar}-\mathrm{H}), 7.34(\mathrm{t}$, $1.5 \mathrm{H}, J=8 \mathrm{~Hz}, A r-\mathbf{H}), 7.61(\mathrm{dd}, 0.5 \mathrm{H}, J=4 \mathrm{~Hz}, 8 \mathrm{~Hz}$, $\mathrm{Ar}-\mathbf{H}), 7.88(\mathrm{dd}, 1.5 \mathrm{H}, J=4 \mathrm{~Hz}, 8 \mathrm{~Hz}, \mathrm{Ar}-\mathrm{H}), 8.16(\mathrm{~s}$, $0.25 \mathrm{H}, \mathrm{H}-\mathrm{C}=\mathrm{N}), 8.39(\mathrm{~d}, 0.5 \mathrm{H}, J=4 \mathrm{~Hz}, \mathrm{Ar}-\mathrm{H}), 8.53(\mathrm{~s}$, $0.75 \mathrm{H}, \mathrm{H}-\mathrm{C}=\mathrm{N}), 8.54(\mathrm{~d}, 1.5 \mathrm{H}, J=4 \mathrm{~Hz}, \mathrm{Ar}-\mathrm{H}), 9.25(\mathrm{~d}$, $0.5 \mathrm{H}, J=8 \mathrm{~Hz}, \mathrm{Ar}-\mathbf{H}), 9.33$ (d, $1.5 \mathrm{H}, J=4 \mathrm{~Hz}, \mathrm{Ar}-\mathbf{H}$ ), 12.51 (bs, $1 \mathrm{H}, \mathrm{CONH}) .{ }^{13} \mathrm{C}$ NMR $(100 \mathrm{MHz}, \mathrm{DMSO}-$ $\left.d_{6}\right): \delta_{\mathrm{C}}=13.89\left(\mathrm{CH}_{3}\right), 22.03,25.36,28.33,28.65,28.73$, 28.86, 28.95, 30.48, 30.63, 31.24 $\left(10 \times \mathrm{CH}_{2}\right), 60.96,61.01$ $\left(\mathrm{NCH}_{2}\right), 115.73,115.94,116.16,126.14,127.11,129.34$, $129.43,129.70,129.79,130.25,130.28,145.08,145.67$, 147.37, 149.39, 149.66 (Ar-C), 158.75, 162.27, 164.75, $165.19(\mathbf{C}=\mathrm{N}, \mathbf{C}=\mathrm{O}) .{ }^{19} \mathrm{~F}$ NMR (377 MHz, DMSO- $\left.d_{6}\right)$ : $\delta_{\mathrm{F}}=-73.53\left(\mathrm{~s}, 3 \mathrm{~F}, \mathrm{CF}_{3}\right),(-109.97$ to -109.89$),(-109.48$ to -109.40$)(2 \mathrm{~m}, 1 \mathrm{~F}, \mathrm{Ar}-\mathrm{F})$. MS (ES) $m / z=525.20\left[\mathrm{M}^{+}\right]$.

4-(2-(4-Fluorobenzylidene)hydrazinecarbonyl)-1-tetradecylpyridin-1-ium hexafluorophosphte (25) It was obtained as yellow syrup. ${ }^{1} \mathrm{H}$ NMR $(400 \mathrm{MHz}, \mathrm{DMSO}-$ $\left.d_{6}\right): \delta_{\mathrm{H}}=0.83-0.87\left(\mathrm{~m}, 3 \mathrm{H}, \mathrm{CH}_{3}\right), 1.24-1.30(\mathrm{~m}, 22 \mathrm{H}$, $\left.11 \times \mathrm{CH}_{2}\right), 1.96-1.99\left(\mathrm{~m}, 2 \mathrm{H}, \mathrm{NCH}_{2} \mathrm{CH}_{2}\right), 4.68(\mathrm{t}, 2 \mathrm{H}$, $\left.J=8 \mathrm{~Hz}, \mathrm{NCH}_{2}\right), 7.22(\mathrm{t}, 0.5 \mathrm{H}, J=8 \mathrm{~Hz}, \mathrm{Ar}-\mathbf{H}), 7.34(\mathrm{t}$, $1.5 \mathrm{H}, J=8 \mathrm{~Hz}, \mathrm{Ar}-\mathbf{H}), 7.61(\mathrm{dd}, 0.5 \mathrm{H}, J=4 \mathrm{~Hz}, 8 \mathrm{~Hz}$, $\mathrm{Ar}-\mathbf{H}), 7.89$ (dd, $1.5 \mathrm{H}, J=4 \mathrm{~Hz}, 8 \mathrm{~Hz}, \mathrm{Ar}-\mathbf{H}), 8.16(\mathrm{~s}$, $0.25 \mathrm{H}, \mathbf{H}-\mathrm{C}=\mathrm{N}), 8.39(\mathrm{~d}, 0.5 \mathrm{H}, J=4 \mathrm{~Hz}, \mathrm{Ar}-\mathbf{H}), 8.50(\mathrm{~s}$, $0.75 \mathrm{H}, \mathrm{H}-\mathrm{C}=\mathrm{N}), 8.53(\mathrm{~d}, 1.5 \mathrm{H}, J=8 \mathrm{~Hz}, \mathrm{Ar}-\mathrm{H}), 9.24(\mathrm{~d}$, $0.5 \mathrm{H}, J=8 \mathrm{~Hz}, \mathrm{Ar}-\mathbf{H}), 9.33(\mathrm{~d}, 1.5 \mathrm{H}, J=8 \mathrm{~Hz}, \mathrm{Ar}-\mathbf{H})$, 12.44 (s, 0.75H, CONH), 12.49 (s, $0.25 \mathrm{H}, \mathrm{CONH}) .{ }^{13} \mathrm{C}$ NMR $\left(100 \mathrm{MHz}\right.$, DMSO- $\left.d_{6}\right): \delta_{\mathrm{C}}=13.88\left(\mathrm{CH}_{3}\right), 22.03$, 25.36, 28.33, 28.65, 28.73, 28.86, 28.95, 28.99, 30.48, 30.62, 31.24, 32.84 $\left(12 \times \mathrm{CH}_{2}\right), 60.97,61.04\left(\mathrm{NCH}_{2}\right), 115.73$, $115.94,116.16,126.14,127.11,129.34,129.43,129.72$, $129.81,130.07,130.21,130.24,145.07,145.68,147.32$, 149.38 (Ar-C), 158.73, 162.29, 164.77, $165.19(\mathrm{C}=\mathrm{N}$, 
$\mathrm{C}=\mathrm{O}) .{ }^{31} \mathrm{P}$ NMR $\left(162 \mathrm{MHz}, \mathrm{DMSO}-d_{6}\right): \delta_{\mathrm{p}}=-152.97$ to $-135.41\left(\mathrm{~m}, 1 \mathrm{P}, \mathrm{PF}_{6}\right) .{ }^{19} \mathrm{~F}$ NMR $\left(377 \mathrm{MHz}, \mathrm{DMSO}-d_{6}\right)$ : $\delta_{\mathrm{F}}=-69.26\left(\mathrm{~d}, 6 \mathrm{~F}, \mathrm{PF}_{6}\right),(-109.96$ to -109.89$),(-109.44$ to -109.36$)(2 \mathrm{~m}, 1 \mathrm{~F}, \mathrm{Ar}-\mathbf{F})$. MS (ES) $m / z=585.50\left[\mathrm{M}^{+}\right]$.

4-(2-(4-Fluorobenzylidene)hydrazinecarbonyl)-1-tetradecylpyridin-1-ium tetrafluoroborate (26) It was obtained as yellow syrup. ${ }^{1} \mathrm{H}$ NMR $(400 \mathrm{MHz}, \mathrm{DMSO}-$ $\left.d_{6}\right): \delta_{\mathrm{H}}=0.85\left(\mathrm{t}, 3 \mathrm{H}, J=8 \mathrm{~Hz}, \mathrm{CH}_{3}\right), 1.24-1.30(\mathrm{~m}, 22 \mathrm{H}$, $\left.11 \times \mathrm{CH}_{2}\right), 1.96-1.99\left(\mathrm{~m}, 2 \mathrm{H}, \mathrm{NCH}_{2} \mathrm{CH}_{2}\right), 4.68(\mathrm{t}, 2 \mathrm{H}$, $\left.J=8 \mathrm{~Hz}, \mathrm{NCH}_{2}\right), 7.22(\mathrm{t}, 0.5 \mathrm{H}, J=8 \mathrm{~Hz}, \mathrm{Ar}-\mathbf{H}), 7.34(\mathrm{t}$, $1.5 \mathrm{H}, J=8 \mathrm{~Hz}, \operatorname{Ar}-\mathbf{H}), 7.62(\mathrm{dd}, 0.5 \mathrm{H}, J=4 \mathrm{~Hz}, 8 \mathrm{~Hz}$, Ar-H), 7.89 (dd, $1.5 \mathrm{H}, J=4 \mathrm{~Hz}, 8 \mathrm{~Hz}, \mathrm{Ar}-\mathbf{H}), 8.16(\mathrm{~s}$, $0.25 \mathrm{H}, \mathbf{H}-\mathrm{C}=\mathrm{N}), 8.39(\mathrm{~d}, 0.5 \mathrm{H}, J=4 \mathrm{~Hz}, \mathrm{Ar}-\mathbf{H}), 8.50(\mathrm{~s}$, $0.75 \mathrm{H}, \mathbf{H}-\mathrm{C}=\mathrm{N}), 8.53(\mathrm{~d}, 1.5 \mathrm{H}, J=8 \mathrm{~Hz}, \mathrm{Ar}-\mathrm{H}), 9.25(\mathrm{~d}$, $0.5 \mathrm{H}, J=8 \mathrm{~Hz}, \mathrm{Ar}-\mathbf{H}), 9.33(\mathrm{~d}, 1.5 \mathrm{H}, J=4 \mathrm{~Hz}, \mathrm{Ar}-\mathbf{H})$, 12.44 (s, 0.75H, CONH), 12.49 (s, $0.25 \mathrm{H}, \mathrm{CONH}) .{ }^{13} \mathrm{C}$ NMR $\left(100 \mathrm{MHz}\right.$, DMSO- $\left.d_{6}\right): \delta_{\mathrm{C}}=13.88\left(\mathrm{CH}_{3}\right), 22.03$, 25.36, 28.34, 28.65, 28.74, 28.87, 28.96, 28.99, 30.48, 30.62, 31.24 $\left(12 \times \mathrm{CH}_{2}\right), 60.96,61.03\left(\mathrm{NCH}_{2}\right), 115.73,115.94$, $116.16,126.14,127.11,129.34,129.43,129.72,129.81$, 130.07, 130.21, 130.24, 145.08, 145.69, 147.32, 149.38, 149.66 (Ar-C), 158.72, 162.29, 164.77, $165.19(\mathbf{C}=\mathrm{N}$, $\mathrm{C}=\mathrm{O}) .{ }^{11} \mathrm{~B}$ NMR (128 MHz, DMSO- $\left.d_{6}\right): \delta_{\mathrm{B}}=-1.30$ to $-1.29\left(\mathrm{~m}, 1 \mathrm{~B}, \mathrm{BF}_{4}\right) \cdot{ }^{19} \mathrm{~F}$ NMR (377 MHz, DMSO- $\left.d_{6}\right)$ : $\delta_{\mathrm{F}}=(-109.97$ to -109.89$),(-109.45$ to -109.37$)(2 \mathrm{~m}$, 1F, Ar-F); - 148.37, - 148.32 (2d, 4F, $\mathrm{BF}_{4}$ ). MS (ES) $m / z=527.40\left[\mathrm{M}^{+}\right]$.

4-(2-(4-Fluorobenzylidene)hydrazinecarbonyl)-1-tetradecylpyridin-1-ium trifluoroacetate (27) It was obtained as colorless syrup. ${ }^{1} \mathrm{H}$ NMR (400 MHz, DMSO- $\left.d_{6}\right)$ : $\delta_{\mathrm{H}}=0.85\left(\mathrm{t}, 3 \mathrm{H}, J=8 \mathrm{~Hz}, \mathrm{CH}_{3}\right), 1.24-1.30(\mathrm{~m}, 22 \mathrm{H}$, $\left.11 \times \mathrm{CH}_{2}\right), 1.96-1.98\left(\mathrm{~m}, 2 \mathrm{H}, \mathrm{NCH}_{2} \mathrm{CH}_{2}\right), 4.68(\mathrm{t}, 2 \mathrm{H}$, $\left.J=8 \mathrm{~Hz}, \mathrm{NCH}_{2}\right), 7.22(\mathrm{t}, 0.5 \mathrm{H}, J=8 \mathrm{~Hz}, \mathrm{Ar}-\mathbf{H}), 7.34(\mathrm{t}$, $1.5 \mathrm{H}, J=8 \mathrm{~Hz}, \mathrm{Ar}-\mathbf{H}), 7.61(\mathrm{dd}, 0.5 \mathrm{H}, J=4 \mathrm{~Hz}, 8 \mathrm{~Hz}$, Ar-H), 7.88 (dd, $1.5 \mathrm{H}, J=4 \mathrm{~Hz}, 8 \mathrm{~Hz}, \mathrm{Ar}-\mathrm{H}), 8.16(\mathrm{~s}$, $0.25 \mathrm{H}, \mathrm{H}-\mathrm{C}=\mathrm{N}), 8.39(\mathrm{~d}, 0.5 \mathrm{H}, J=4 \mathrm{~Hz}, \mathrm{Ar}-\mathrm{H}), 8.51(\mathrm{~s}$, $0.75 \mathrm{H}, \mathrm{H}-\mathrm{C}=\mathrm{N}), 8.53(\mathrm{~d}, 1.5 \mathrm{H}, J=4 \mathrm{~Hz}, \mathrm{Ar}-\mathrm{H}), 9.25(\mathrm{~d}$, $0.5 \mathrm{H}, J=8 \mathrm{~Hz}, \mathrm{Ar}-\mathbf{H}), 9.33(\mathrm{~d}, 1.5 \mathrm{H}, J=4 \mathrm{~Hz}, \mathrm{Ar}-\mathrm{H})$, 12.47 (s, 0.75H, CONH), 12.49 (s, $0.25 \mathrm{H}, \mathrm{CONH}) .{ }^{13} \mathrm{C}$ NMR $\left(100 \mathrm{MHz}\right.$, DMSO- $\left.d_{6}\right): \delta_{\mathrm{C}}=13.88\left(\mathrm{CH}_{3}\right), 22.03$, 25.36, 28.33, 28.65, 28.74, 28.86, 28.95, 28.99, 30.49, 30.62, 31.24 $\left(12 \times \mathrm{CH}_{2}\right), 60.95,61.03\left(\mathrm{NCH}_{2}\right), 115.72$, $115.94,116.16,126.14,127.11,129.34,129.43,129.71$, $129.80,130.22,130.25,145.08,145.69,147.32,149.38$, 149.66 (Ar-C), 158.73, 162.29, 164.76, $165.19(\mathbf{C}=\mathrm{N}$, $\mathrm{C}=\mathrm{O}) .{ }^{19} \mathrm{~F}$ NMR $\left(377 \mathrm{MHz}, \mathrm{DMSO}-d_{6}\right): \delta_{\mathrm{F}}=-73.55(\mathrm{~s}$, 3F, $\left.\mathrm{CF}_{3}\right),(-109.97$ to -109.89$),(-109.45$ to -109.38$)$ (2m, 1F, Ar-F). MS (ES) $m / z=553.30\left[\mathrm{M}^{+}\right]$.

4-(2-(4-Fluorobenzylidene)hydrazinecarbonyl)-1-hexadecylpyridin-1-ium hexaflurophosphate (28) It was obtained as yellow syrup. ${ }^{1} \mathrm{H}$ NMR $(400 \mathrm{MHz}$, DMSO$\left.d_{6}\right): \delta_{\mathrm{H}}=0.83-0.88\left(\mathrm{~m}, 3 \mathrm{H}, \mathrm{CH}_{3}\right), 1.23-1.30(\mathrm{~m}, 26 \mathrm{H}$, $\left.13 \times \mathrm{CH}_{2}\right), 1.96-2.00\left(\mathrm{~m}, 2 \mathrm{H}, \mathrm{NCH}_{2} \mathrm{CH}_{2}\right), 4.68(\mathrm{t}, 2 \mathrm{H}$, $\left.J=8 \mathrm{~Hz}, \mathrm{NCH}_{2}\right), 7.24(\mathrm{dd}, 0.5 \mathrm{H}, J=8 \mathrm{~Hz}, 12 \mathrm{~Hz}, \mathrm{Ar}-\mathbf{H})$, $7.34(\mathrm{t}, 1.5 \mathrm{H}, J=8 \mathrm{~Hz}, \mathrm{Ar}-\mathbf{H}), 7.62(\mathrm{dd}, 0.5 \mathrm{H}, J=4 \mathrm{~Hz}$, $8 \mathrm{~Hz}, \mathrm{Ar}-\mathbf{H}), 7.89$ (dd, $1.5 \mathrm{H}, J=4 \mathrm{~Hz}, 8 \mathrm{~Hz}, \mathrm{Ar}-\mathbf{H}), 8.16$ $(\mathrm{s}, 0.25 \mathrm{H}, \mathbf{H}-\mathrm{C}=\mathrm{N}), 8.39(\mathrm{~d}, 0.5 \mathrm{H}, J=4 \mathrm{~Hz}, \mathrm{Ar}-\mathbf{H}), 8.51$ $(\mathrm{s}, 0.75 \mathrm{H}, \mathbf{H}-\mathrm{C}=\mathrm{N}), 8.53(\mathrm{~d}, 1.5 \mathrm{H}, J=4 \mathrm{~Hz}, \mathrm{Ar}-\mathbf{H}), 9.25$ $(\mathrm{d}, 0.5 \mathrm{H}, J=8 \mathrm{~Hz}, \mathrm{Ar}-\mathbf{H}), 9.33(\mathrm{~d}, 1.5 \mathrm{H}, J=4 \mathrm{~Hz}, \mathrm{Ar}-\mathbf{H})$, 12.44 (s, 0.75H, CONH), 12.49 (s, 0.25H, CONH). ${ }^{13} \mathrm{C}$ NMR $\left(100 \mathrm{MHz}, \mathrm{DMSO}-d_{6}\right): \delta_{\mathrm{C}}=13.88\left(\mathrm{CH}_{3}\right), 22.03$, $25.36,28.34,28.64,28.74,28.87,28.96,29.00,30.49$, 30.62, 31.24 $\left(14 \times \mathrm{CH}_{2}\right), 60.96,61.03\left(\mathrm{NCH}_{2}\right), 115.72$, $115.94,116.15,126.13,127.11,129.34,129.43,129.72$, $129.81,130.21,130.24,145.07,145.69,147.32,149.37$, 149.65 (Ar-C), 158.71, 162.29, 164.76, $165.18(\mathrm{C}=\mathrm{N}$, $\mathrm{C}=\mathrm{O}) .{ }^{31} \mathrm{P}$ NMR $\left(162 \mathrm{MHz}, \mathrm{DMSO}-d_{6}\right): \delta_{\mathrm{P}}=-152.97$ to $-135.41\left(\mathrm{~m}, 1 \mathrm{P}, \mathrm{PF}_{6}\right) .{ }^{19} \mathrm{~F}$ NMR (377 MHz, DMSO- $d_{6}$ ): $\delta_{\mathrm{F}}=-69.26\left(\mathrm{~d}, 6 \mathrm{~F}, \mathrm{PF}_{6}\right),(-109.97$ to -109.89$),(-109.45$ to -109.37$)(2 \mathrm{~m}, 1 \mathrm{~F}, \mathrm{Ar}-\mathrm{F})$. MS (ES) $m / z=613.30\left[\mathrm{M}^{+}\right]$.

4-(2-(4-Fluorobenzylidene)hydrazinecarbonyl)-1-hexadecylpyridin-1-ium tetrafluoroborate (29) It was obtained as yellow syrup. ${ }^{1} \mathrm{H}$ NMR $(400 \mathrm{MHz}$, DMSO$\left.d_{6}\right): \delta_{\mathrm{H}}=0.83-0.87\left(\mathrm{~m}, 3 \mathrm{H}, \mathrm{CH}_{3}\right), 1.23-1.30(\mathrm{~m}, 26 \mathrm{H}$, $\left.13 \times \mathrm{CH}_{2}\right), 1.94-2.00\left(\mathrm{~m}, 2 \mathrm{H}, \mathrm{NCH}_{2} \mathrm{CH}_{2}\right), 4.70(\mathrm{dd}, 2 \mathrm{H}$, $\left.J=4 \mathrm{~Hz}, 8 \mathrm{~Hz}, \mathrm{NCH}_{2}\right), 7.24(\mathrm{dd}, 0.5 \mathrm{H}, J=8 \mathrm{~Hz}, 12 \mathrm{~Hz}$, $\mathrm{Ar}-\mathrm{H}), 7.34(\mathrm{t}, 1.5 \mathrm{H}, J=8 \mathrm{~Hz}, \mathrm{Ar}-\mathrm{H}), 7.62(\mathrm{dd}, 0.5 \mathrm{H}$, $J=4 \mathrm{~Hz}, 8 \mathrm{~Hz}, \mathrm{Ar}-\mathrm{H}), 7.88(\mathrm{dd}, 1.5 \mathrm{H}, J=4 \mathrm{~Hz}, 8 \mathrm{~Hz}$, $\mathrm{Ar}-\mathrm{H}), 8.16(\mathrm{~s}, 0.25 \mathrm{H}, \mathrm{H}-\mathrm{C}=\mathrm{N}), 8.39(\mathrm{~d}, 0.5 \mathrm{H}, J=4 \mathrm{~Hz}$, Ar-H), $8.51(\mathrm{~s}, 0.75 \mathrm{H}, \mathbf{H}-\mathrm{C}=\mathrm{N}), 8.53(\mathrm{~d}, 1.5 \mathrm{H}, J=4 \mathrm{~Hz}$, $\mathrm{Ar}-\mathbf{H}), 9.25(\mathrm{~d}, 0.5 \mathrm{H}, J=4 \mathrm{~Hz}, \mathrm{Ar}-\mathrm{H}), 9.34(\mathrm{~d}, 1.5 \mathrm{H}$, $J=4 \mathrm{~Hz}, \mathrm{Ar}-\mathrm{H}), 12.45(\mathrm{~s}, 0.75 \mathrm{H}, \mathrm{CONH}), 12.49(\mathrm{~s}, 0.25 \mathrm{H}$, CONH). ${ }^{13} \mathrm{C}$ NMR (100 MHz, DMSO- $\left.d_{6}\right): \delta_{\mathrm{C}}=13.88$ $\left(\mathrm{CH}_{3}\right), 22.03,25.36,28.34,28.65,28.75,28.87,28.96$, $29.00,30.49,30.63,31.24\left(14 \times \mathrm{CH}_{2}\right), 60.96,61.03\left(\mathrm{NCH}_{2}\right)$, $115.72,115.93,116.15,126.13,127.11,129.35,129.43$, $129.72,129.80,130.04,130.21,130.24,145.07,145.69$, 147.30, 149.37, 149.64 (Ar-C), 158.71, 162.28, 164.76, $165.17(\mathbf{C}=\mathrm{N}, \mathbf{C}=\mathrm{O}) .{ }^{11} \mathrm{~B}$ NMR (128 MHz, DMSO- $\left.d_{6}\right)$ : $\delta_{\mathrm{B}}=-1.29$ to $-1.28\left(\mathrm{~m}, 1 \mathrm{~B}, \mathrm{BF}_{4}\right) \cdot{ }^{19} \mathrm{~F}$ NMR $(377 \mathrm{MHz}$, DMSO- $\left.d_{6}\right): \delta_{\mathrm{F}}=(-109.97$ to -109.90$), \quad(-109.46$ to -109.38) (2m, 1F, Ar-F); - 148.36, - 148.31 (2d, 4F, $\left.\mathrm{BF}_{4}\right) . \mathrm{MS}(\mathrm{ES}) m / z=555.35\left[\mathrm{M}^{+}\right]$.

4-(2-(4-Fluorobenzylidene)hydrazinecarbonyl)-1-hexadecylpyridin-1-ium trifluoroacetate (30) It was obtained as colorless syrup. ${ }^{1} \mathrm{H}$ NMR $(400 \mathrm{MHz}$, DMSO- $\left.d_{6}\right): \delta_{\mathrm{H}}=0.85\left(\mathrm{t}, 3 \mathrm{H}, J=8 \mathrm{~Hz}, \mathrm{CH}_{3}\right), 1.23-1.30$ $\left(\mathrm{m}, 26 \mathrm{H}, 13 \times \mathrm{CH}_{2}\right), 1.96-1.98\left(\mathrm{~m}, 2 \mathrm{H}, \mathrm{NCH}_{2} \mathrm{CH}_{2}\right)$, $4.69\left(\mathrm{dd}, 2 \mathrm{H}, J=4 \mathrm{~Hz}, 8 \mathrm{~Hz}, \mathrm{NCH}_{2}\right), 7.22(\mathrm{t}, 0.5 \mathrm{H}$, $J=8 \mathrm{~Hz}, \operatorname{Ar}-\mathbf{H}), 7.34(\mathrm{t}, 1.5 \mathrm{H}, J=8 \mathrm{~Hz}, \mathrm{Ar}-\mathbf{H}), 7.61(\mathrm{dd}$, $0.5 \mathrm{H}, J=4 \mathrm{~Hz}, 8 \mathrm{~Hz}, \mathrm{Ar}-\mathrm{H}), 7.88(\mathrm{dd}, 1.5 \mathrm{H}, J=4 \mathrm{~Hz}$, 
$8 \mathrm{~Hz}, \mathrm{Ar}-\mathbf{H}), 8.16(\mathrm{~s}, 0.25 \mathrm{H}, \mathrm{H}-\mathrm{C}=\mathrm{N}), 8.39(\mathrm{~d}, 0.5 \mathrm{H}$, $J=4 \mathrm{~Hz}, \mathrm{Ar}-\mathrm{H}), 8.52(\mathrm{~s}, 0.75 \mathrm{H}, \mathrm{H}-\mathrm{C}=\mathrm{N}), 8.54(\mathrm{~d}, 1.5 \mathrm{H}$, $J=8 \mathrm{~Hz}, \mathrm{Ar}-\mathbf{H}), 9.25(\mathrm{~d}, 0.5 \mathrm{H}, J=8 \mathrm{~Hz}, \mathrm{Ar}-\mathbf{H}), 9.33$ (d, $1.5 \mathrm{H}, J=8 \mathrm{~Hz}, \mathrm{Ar}-\mathrm{H}), 12.50(\mathrm{~s}, 1 \mathrm{H}, \mathrm{CONH}) .{ }^{13} \mathrm{C}$ NMR (100 MHz, DMSO- $\left.d_{6}\right): \delta_{\mathrm{C}}=13.88\left(\mathrm{CH}_{3}\right), 22.03$, $25.35,28.33,28.64,28.73,28.86,28.95,29.00,30.49$, 30.62, $31.23\left(14 \times \mathrm{CH}_{2}\right), 60.95,61.02\left(\mathrm{NCH}_{2}\right), 115.72$, $115.94,116.16,126.14,127.11,129.33,129.42,129.71$, $129.80,130.08,130.26,145.08,145.68,147.33,149.39$ (Ar-C), 158.73, 162.29, 164.76, $165.19(\mathbf{C}=\mathrm{N}, \mathbf{C}=\mathrm{O}) .{ }^{19} \mathrm{~F}$ NMR (377 MHz, DMSO- $\left.d_{6}\right): \delta_{\mathrm{F}}=-73.52\left(\mathrm{~s}, 3 \mathrm{~F}, \mathrm{CF}_{3}\right.$ ), $(-109.96$ to -109.88$)$, ( -109.46 to -109.38$)(2 \mathrm{~m}, 1 \mathrm{~F}$, $\operatorname{Ar}-\mathbf{F})$. MS (ES) $m / z=581.30\left[\mathrm{M}^{+}\right]$.

4-(2-(4-Fluorobenzylidene)hydrazinecarbonyl)-1-octadecylpyridin-1-ium hexafluorophosphate (31) It was obtained as yellow syrup. ${ }^{1} \mathrm{H}$ NMR (400 $\left.\mathrm{MHz}, \mathrm{CDCl}_{3}\right)$ : $\delta_{\mathrm{H}}=0.82\left(\mathrm{dd}, 3 \mathrm{H}, J=4 \mathrm{~Hz}, 8 \mathrm{~Hz}, \mathrm{CH}_{3}\right), 1.15-1.18(\mathrm{~m}$, $\left.30 \mathrm{H}, 15 \times \mathrm{CH}_{2}\right), 1.94-1.98\left(\mathrm{~m}, 2 \mathrm{H}, \mathrm{NCH}_{2} \mathrm{CH}_{2}\right), 4.72(\mathrm{t}$, $2 \mathrm{H}, J=8 \mathrm{~Hz}, \mathrm{NCH}_{2}$ ), 6.95 (t, 2H, $\left.J=8 \mathrm{~Hz}, \mathrm{Ar}-\mathbf{H}\right), 7.67$ $(\mathrm{dd}, 2 \mathrm{H}, J=4 \mathrm{~Hz}, 8 \mathrm{~Hz}, \mathrm{Ar}-\mathrm{H}), 8.82(\mathrm{~d}, 2 \mathrm{H}, J=4 \mathrm{~Hz}$, Ar-H), $9.01(\mathrm{~s}, 1 \mathrm{H}, \mathrm{H}-\mathrm{C}=\mathrm{N}), 9.08(\mathrm{~d}, 2 \mathrm{H}, J=8 \mathrm{~Hz}$, Ar-H), 12.14 (bs, $1 \mathrm{H}, \mathrm{CONH}) .{ }^{13} \mathrm{C}$ NMR $(100 \mathrm{MHz}$, $\left.\mathrm{CDCl}_{3}\right): \delta_{\mathrm{C}}=14.08\left(\mathrm{CH}_{3}\right), 22.66,26.09,28.97,29.33$, $29.49,29.59,29.64,29.68,31.64,31.90\left(16 \times \mathrm{CH}_{2}\right)$, $62.69\left(\mathrm{NCH}_{2}\right), 115.87,116.09,127.71,129.45,130.09$, 130.18, 144.87, 147.76, 151.75 (Ar-C), 158.62, 163.23, 165.74 $(\mathbf{C}=\mathrm{N}, \mathbf{C}=\mathrm{O}) .{ }^{31} \mathrm{P}$ NMR $\left(162 \mathrm{MHz}, \mathrm{CDCl}_{3}\right)$ : $\delta_{\mathrm{P}}=-153.38$ to $-135.76\left(\mathrm{~m}, 1 \mathrm{P}, \mathbf{P F}_{6}\right) .{ }^{19} \mathrm{~F}$ NMR $\left(377 \mathrm{MHz}, \mathrm{CDCl}_{3}\right): \delta_{\mathrm{F}}=-70.39$ (d, 6F, PF $)$, (-107.98 to -107.89$)$, $(-107.72$ to -107.65$)(2 \mathrm{~m}, 1 \mathrm{~F}, \mathrm{Ar}-\mathrm{F})$. MS (ES) $m / z=641.55\left[\mathrm{M}^{+}\right]$.

4-(2-(4-Fluorobenzylidene)hydrazinecarbonyl)-1-octadecylpyridin-1-ium tetrafluoroborate (32) It was obtained as yellow syrup. ${ }^{1} \mathrm{H}$ NMR $\left(400 \mathrm{MHz}, \mathrm{CDCl}_{3}\right): \delta_{\mathrm{H}}=0.82$ $\left(\mathrm{dd}, 3 \mathrm{H}, J=4 \mathrm{~Hz}, 8 \mathrm{~Hz}, \mathrm{CH}_{3}\right), 1.16-1.20(\mathrm{~m}, 30 \mathrm{H}$, 15 $\left.\times \mathrm{CH}_{2}\right), 1.94-1.98\left(\mathrm{~m}, 2 \mathrm{H}, \mathrm{NCH}_{2} \mathrm{CH}_{2}\right), 4.73(\mathrm{t}, 2 \mathrm{H}$, $J=8 \mathrm{~Hz}, \mathrm{NCH}_{2}$ ), 6.99 (dd, $\left.2 \mathrm{H}, J=8 \mathrm{~Hz}, 12 \mathrm{~Hz}, \mathrm{Ar}-\mathbf{H}\right)$, 7.69 (dd, $2 \mathrm{H}, J=4 \mathrm{~Hz}, 8 \mathrm{~Hz}, \mathrm{Ar}-\mathrm{H}), 8.83(\mathrm{~d}, 2 \mathrm{H}, J=8 \mathrm{~Hz}$, Ar-H), $9.00(\mathrm{~s}, 1 \mathrm{H}, \mathbf{H}-\mathrm{C}=\mathrm{N}), 9.06(\mathrm{~d}, 2 \mathrm{H}, J=4 \mathrm{~Hz}$, Ar-H), 12.11 (bs, $1 \mathrm{H}, \mathrm{CONH}) .{ }^{13} \mathrm{C}$ NMR $(100 \mathrm{MHz}$, $\left.\mathrm{CDCl}_{3}\right): \delta_{\mathrm{C}}=14.08\left(\mathrm{CH}_{3}\right), 22.66,26.10,28.97,29.33$, 29.48, 29.57, 29.63, 29.68, 31.66, $31.90\left(16 \times \mathrm{CH}_{2}\right), 62.64$ $\left(\mathrm{NCH}_{2}\right), 115.85,116.07,127.76,129.46,130.12,130.21$, 144.82, 147.96, 151.72 (Ar-C), 158.57, 163.25, 165.76 $(\mathbf{C}=\mathrm{N}, \mathbf{C}=\mathrm{O}) .{ }^{11} \mathrm{~B}$ NMR $\left(128 \mathrm{MHz}, \mathrm{CDCl}_{3}\right): \delta_{\mathrm{B}}=-1.29$ to $1.28\left(\mathrm{~m}, 1 \mathrm{~B}, \mathrm{BF}_{4}\right) .{ }^{19} \mathrm{~F} \mathrm{NMR}\left(377 \mathrm{MHz}, \mathrm{CDCl}_{3}\right)$ : $\delta_{\mathrm{F}}=(-107.98$ to -107.85$)$ to $(107.82$ to -107.75$)$ (2m, 1F, Ar-F); - 149.14, 149.19 (2d, 4F, BF B $_{4}$. MS (ES) $m / z=583.45\left[\mathrm{M}^{+}\right]$.
4-(2-(4-Fluorobenzylidene)hydrazinecarbonyl)-1-octadecylpyridin-1-ium trifluoroacetate (33) It was obtained as colorless syrup. ${ }^{1} \mathrm{H} \mathrm{NMR}\left(400 \mathrm{MHz}, \mathrm{CDCl}_{3}\right): \delta_{\mathrm{H}}=0.82$ (dd, 3H, J=4 Hz, $\left.8 \mathrm{~Hz}, \mathrm{CH}_{3}\right), 1.16-1.19(\mathrm{~m}, 30 \mathrm{H}$, 15 $\left.\times \mathrm{CH}_{2}\right), 1.95-1.99\left(\mathrm{~m}, 2 \mathrm{H}, \mathrm{NCH}_{2} \mathrm{CH}_{2}\right), 4.75(\mathrm{t}, 2 \mathrm{H}$, $\left.J=8 \mathrm{~Hz}, \mathrm{NCH}_{2}\right), 6.96(\mathrm{t}, 2 \mathrm{H}, J=8 \mathrm{~Hz}, \mathrm{Ar}-\mathbf{H}), 7.68(\mathrm{dd}$, $2 \mathrm{H}, J=4 \mathrm{~Hz}, 8 \mathrm{~Hz}, \mathrm{Ar}-\mathbf{H}), 8.84(\mathrm{~d}, 2 \mathrm{H}, J=8 \mathrm{~Hz}, \mathrm{Ar}-\mathbf{H})$, $8.94(\mathrm{~s}, 1 \mathrm{H}, \mathrm{H}-\mathrm{C}=\mathrm{N}), 9.12(\mathrm{~d}, 2 \mathrm{H}, J=4 \mathrm{~Hz}, \mathrm{Ar}-\mathrm{H})$, 12.46 (bs, $1 \mathrm{H}, \mathrm{CONH}) .{ }^{13} \mathrm{C}$ NMR $\left(100 \mathrm{MHz}, \mathrm{CDCl}_{3}\right)$ : $\delta_{\mathrm{C}}=14.07\left(\mathrm{CH}_{3}\right), 22.66,26.09,28.96,29.33,29.47,29.57$, $29.63,29.68,31.66,31.90\left(16 \times \mathrm{CH}_{2}\right), 62.66\left(\mathrm{NCH}_{2}\right)$, $115.85,116.07,127.72,129.53,130.09,130.17,144.87$, 148.01, 151.77 (Ar-C), 158.62, 163.22, $165.73(\mathbf{C}=\mathrm{N}$, $\mathrm{C}=\mathrm{O}) .{ }^{19} \mathrm{~F}$ NMR $\left(377 \mathrm{MHz}, \mathrm{CDCl}_{3}\right): \delta_{\mathrm{F}}=-75.30(\mathrm{~s}, 3 \mathrm{~F}$, $\left.\mathrm{CF}_{3}\right),(-108.01$ to -107.94$),(-107.85$ to -107.78$)(2 \mathrm{~m}$, $1 \mathrm{~F}, \mathrm{Ar}-\mathbf{F})$. MS (ES) $m / z=609.35\left[\mathrm{M}^{+}\right]$.

\section{Biological studies Antiproliferative activity}

MCF-7, T47D, HeLa and Caco-II cell lines were cultivated in Dulbecco's modified Eagles medium (DMEM, Biochrom, Berlin, Germany). Cell lines were maintained at $37{ }^{\circ} \mathrm{C}$ and all media were supplemented with $1 \%$ of $2 \mathrm{mM}$ L-glutamine (Lonza), 10\% fetal calf serum (Gibco, Paisley, UK), $50 \mathrm{IU} / \mathrm{ml}$ penicillin/streptomycin (Sigma, St. Louis, MO) and amphotericin B (Sigma, St. Louis, $\mathrm{MO})$. Cells from passage number 10-16 were used. For the antiproliferative activity test, compounds under examination, dissolved in DMSO, were added to the culture medium and incubated for $48 \mathrm{~h}$ incubation period in an atmosphere of $5 \% \mathrm{CO}_{2}$ and 95 relative humidity at $37^{\circ} \mathrm{C}$.

Cells were seeded at a density of $8 \times 10^{3}$ cells per well in 96-well plates in appropriate medium. When the exposure period ends, Promega Cell Titer 96 Aqueous NonRadioactive Cell Proliferation (MTS) assay was carried out according to the manufacturer's protocol. Absorbance values of each well were determined with a microplate enzyme-linked immuno-assay (ELISA) reader equipped with a $492 \mathrm{~nm}$ filter. Survival rates of the controls were set to represent $100 \%$ viability. Untreated cultures were used as controls groups.

\section{Caspase-3 enzyme activity}

To assess changes in caspase- 3 activity, the caspase- 3 colorimetric assay kit (BioVision Research Products, Milpitas, CA) was used after treatment with $100 \mu \mathrm{M}$ of each compound and incubation for $48 \mathrm{~h}$. Briefly, apoptosis was provoked in treated cells before cells were collected by centrifugation at $1000 \mathrm{rpm}$ for $10 \mathrm{~min}$. Cells were lysed 
and supernatants were separated according to the manufacture's protocol. Protein concentration in the supernatant was determined using the Bradford method. $50 \mu \mathrm{l}$ of the reaction buffer, $200 \mu \mathrm{M}$ of DEVD-pNA substrate were added to $50 \mu \mathrm{l}$ supernatant in a 96-well plate and incubated at $37^{\circ} \mathrm{C}$ for $2 \mathrm{~h}$. After incubation, the plate was read under $405 \mathrm{~nm}$ wavelength using an ELISA reader (Tecan Group Ltd., Mannedorf, Switzerland).

\section{Computational methods}

\section{Preparation of protein structure}

The crystal structure of apo PI3K $\alpha$ (PDB ID: 2RD0) [(2)] was retrieved from the RCSB Protein Data Bank. The homology modeled structure of 2RD0 was adopted for this study [47]. The coordinates of wortmannin in 3HHM [48] were moved to 2RD0 and assigned as the ligand. Minimization of the protein side chains was applied to reduce the steric clashes recruiting MacroModel [20] module in MAESTRO. Further preparation of the coordinates was carried out using Protein Preparation [20] wizard in Schrödinger to maximize the H-bond interactions between residues.

\section{Preparation of ligand structures}

The synthesized compounds (ligands) were built based on the coordinates of wortmannin in 3 HHM. The ligands were built using MAESTRO [20] BUILD module and then subjected for energy minimization using OPLS2005 force field in MacroModel program.

\section{Quantum-polarized ligand docking (QPLD)}

QPLD [20,45] (3, 4) docking employed the combined $\mathrm{QM} / \mathrm{MM}$ approach to determine ligand/protein complex formation. The Glide [49-51] docking was implemented in QPLD to generate a list of ligand docked poses that fit the protein binding site. The binding energy of the protein/newly generated ligand pose was derived using the molecular mechanical (MM) method for the protein coordinates while the quantum mechanical (QM) method was applied for ligand pose recruiting the QSite wizard in Schrödinger [45]. The Qsite program generated the atomic partial charges for the ligand pose within the protein environment. The ligand pose with QM-generated partial charges were redocked to the binding pocket using Glide [45] program with XP-scoring function. Specifically, the polarization effect of the protein binding pocket was accounted during the docking procedure. The ligand pose with the lowest root mean square deviation (RMSD) was investigated. The kinase binding domain was defined using the ligand as a centroid. The scaling of receptor Vander Waals for the non-polar atoms was set to 0.75 .

\section{Conclusions}

Novel cationic fluorinated pyridinium hydrazones tethering lipophilic side chain were designed and synthesized under both conventional and green ultrasound conditions. The synthesized compounds were assessed for their anticancer activities and the results revealed that adding to the length of the hydrophobic chain significantly enhances their anticancer activities. Considerable increase in caspase- 3 activity was associated with the most potent compounds, namely $8,28,29$ and 32 suggesting an apoptotic cellular death pathway. Molecular Docking studies employing QPLD approach against PI3K $\alpha$ demonstrated that compounds 2-9 accommodate the kinase site and form H-bond with S774, K802, H917, and D933 (Additional file 1).

\section{Additional file}

Additional file 1. Additional figures.

\section{Authors' contributions}

NR, MRA, and MM conceived the presented study. NR, FFA and SAS contributed to the design and implementation of the work, to the collection of the experimental results and to the writing of the manuscript. SKB and DAS performed the biological and simulation part. MRA, NR, MM and FFA contributed to the interpretation of the results. All authors provided critical feedback and helped shape the research, analysis and manuscript. All authors read and approved the final manuscript.

\section{Author details \\ ${ }^{1}$ Department of Chemistry, Faculty of Science, Taibah University, Al-Madinah Al-Munawarah, Medina 30002, Saudi Arabia. ${ }^{2}$ Department of Chemistry, Faculty of Sciences, University of Sciences and Technology Mohamed Boudiaf, Laboratoire de Chimie et Electrochimie des Complexes Metalliques (LCECM) USTO-MB, P.O. Box 1505, El M'nouar, 31000 Oran, Algeria. ${ }^{3}$ Depart- ment of Pharmaceutical Sciences, Faculty of Pharmacy, University of Jordan, Amman 11942, Jordan. ${ }^{4}$ Faculty of Pharmacy, Al-Zaytoonah University, Amman 11733, Jordan.}

\section{Competing interests}

The authors declare that they have no competing interests.

Consent for publication

Not applicable.

Ethics approval and consent to participate Not applicable.

\section{Publisher's Note}

Springer Nature remains neutral with regard to jurisdictional claims in published maps and institutional affiliations.

Received: 15 March 2018 Accepted: 13 November 2018 Published online: 22 November 2018 


\section{References}

1. Rollas S, Küçükgüzel SG (2007) Biological activities of hydrazone derivatives. Molecules 12:1910-1939

2. Verma G, Marella A, Shaquiquzzaman M, Akhtar M, Ali MR, Alam MM (2014) A review exploring biological activities of hydrazones. J Pharm Bioallied Sci 6:69-80

3. Pieczonka AM, Strzelczyk A, Sadowska B, Mlostoń G, Stączek P (2013) Synthesis and evaluation of antimicrobial activity of hydrazones derived from 3-oxido-1H-imidazole-4-carbohydrazides. Eur J Med Chem 64:389-395

4. Kumar P, Narasimhan B (2013) Hydrazides/hydrazones as antimicrobial and anticancer agents in the new millennium. Mini Rev Med Chem 13:971-987

5. Ahmed HE, Abdel-Salam HA, Shaker MA (2016) Synthesis, characterization, molecular modeling, and potential antimicrobial and anticancer activities of novel 2-aminoisoindoline-1,3-dione derivatives. Bioorg Chem $6: 1-11$

6. Savini L, Chiasserini L, Travagli V, Pellerano C, Novellino E, Cosentino S, Pisano MB (2004) New alpha-(N)-heterocyclichydrazones: evaluation of anticancer, anti-HIV and antimicrobial activity. Eur J Med Chem 39:113-122

7. Altıntop MD, Özdemir A, Turan-Zitouni G, Ilgın S, Atlı Ö, İşcan G, Kaplancıklı ZA (2012) Synthesis and biological evaluation of some hydrazone derivatives as new anticandidal and anticancer agents. Eur J Med Chem 58:299-307

8. Chen K, Hu Y, Li Q-Sh, Lu X, Yan R, Zhu H-L (2012) Design, synthesis, biological evaluation and molecular modeling of 1,3,4-oxadiazoline analogs of COMBRETASTATIN-A4 as novel antitubulin agents. Bioorg Med Chem 20:903-909

9. Lamaty F, Martin Ch, Martinez J, Nun P (2013) Solvent-free synthesis of hydrazones and their subsequent $\mathrm{N}$-alkylation in a Ball-mill. Tetrahedron 67:8187-8194

10. Tiwari VK, Dubey AK, Dikshit SN (2016) Synthesis, spectral and biological activities of pyridine 2,6 dicarboxalic acid hydrazone derivatives and its metal complexes. J Chem Chem Sci 6:911-918

11. Neha S, Ritu R, Manju K, Birendra K (2016) A review on biological activities of hydrazone derivatives. Int J Pharm Clin Res 8:162-166

12. Padmini K, Preethi PJ, Divya M, Rohini P, Lohita M, Swetha K, Kaladar PA (2013) Review on biological importance of hydrazones. Int J Pharm Res Rev 2:43-58

13. Messali M (2015) Eco-friendly synthesis of a new class of pyridiniumbased ionic liquids with attractive antimicrobial activity. Molecules 20:14936-14949

14. Messali M, Almtiri MN, Abderrahman B, Salghi R, Aouad MR, Alshahateet SF, Ali AA-Sh (2015) New pyridazinium-based ionic liquids: an ecofriendly ultrasound-assisted synthesis, characterization and biological activity. S Afr J Chem 68:219-225

15. Harjani JR, Singer RD, Garcia MT, Scammells PJ (2009) Biodegradable pyridinium ionic liquids: design, synthesis and evaluation. Green Chem 11:83-90

16. Rezki N, Al-Sodies SA, Aouad MR, Bardaweel S, Messali M, El Ashry ESH (2016) An eco-friendly ultrasound-assisted synthesis of novel fluorinated pyridinium salts-based hydrazones and antimicrobial and antitumor screening. Int J Mol Sci 17:766-785

17. Rezki N, Al-Yahyawi AM, Bardaweel SK, Al-Blewi FF, Aouad MR (2015) Synthesis of novel 2,5-disubstituted-1,3,4-thiadiazoles clubbed 1,2,4-Triazole, 1,3,4-thiadiazole, 1,3,4-oxadiazole and/or Schiff base as potential antimicrobial and antiproliferative agents. Molecules 20:16048-16067

18. Aouad MR, Messali M, Rezki N, Ali AA-Sh, Lesimple A (2015) Synthesis and characterization of some novel 1,2,4-triazoles, 1,3,4-thiadiazoles and Schiff bases incorporating imidazole moiety as potential antimicrobial agents. Acta pharmaceutica 65:117-132

19. Aouad MR, Rezki N, Kasmi M, Aouad L, Rezki MA (2012) Synthesis, characterization and evaluation of antimicrobial activity of some novel 1,2,4-triazoles and 1,3,4-thiadiazoles bearing imidazole nucleus. Heterocycles 85:1141-1154

20. Protein Preparation Wizard, Maestro, Macromodel, and QPLD-dock, Schrödinger, LLC, Portland, OR, USA. 97204;2016

21. Huang C-H, Mandelker D, Schmidt-Kittler O, Samuels Y, Velculescu VE, Kinzler KW, Vogelstein B, Gabelli SB, Amzel LM (2007) The structure of a human p110 alpha/p85 alpha complex elucidates the effects of oncogenic PI3K alpha mutations. Science 318:1744-1748

22. Ebi H, Costa C, Faber AC, Nishtala M, Kotani H, Juric D, Della-Pelle P, Song Y, Yano S, Mino-Kenudson M, Benes CH, Engelman JA (2013) PI3 K regulates MEK/ERK signaling in breast cancer via the Rac-GEF, P-Rex1. Proc Natl Acad Sci USA 110:21124-21129

23. Sanchez CG, Ma CX, Crowder RJ, Guintoli T, Phommaly C, Gao F, Lin L, Ellis MJ (2011) Preclinical modeling of combined phosphatidylinositol3-kinase inhibition with endocrine therapy for estrogen receptorpositive breast cancer. Breast Cancer Res 13:R21-R28

24. Spangle JM, Dreijerink KM, Groner AC, Cheng H, Ohlson CE, Reyes J, Lin CY, Bradner J, Zhao JJ, Roberts TM, Brown M (2016) PI3K/AKT signaling regulates H3K4 methylation in breast cancer. Cell Rep 15:2692-2704

25. Kataoka Y, Mukohara T, Shimada H, Saijo N, Hirai M, Minami H (2010) Association between gain-of-function mutations in PIK3CA and resistance to HER2-targeted agents in HER2-amplified breast cancer cell lines. Ann Oncol 21:255-262

26. Sabine VS, Crozier C, Brookes CL, Drake C, Piper T, Van de Velde CJ, Hasenburg A, Kieback DG, Markopoulos C, Dirix L (2014) Mutational analysis of PI3 K/AKT signaling pathway in tamoxifen exemestane adjuvant multinational pathology study. J Clin Oncol 32:2951-2958

27. J-I Liu, Gao G-R, Zhang X, Cao S-F, Guo C-L, Wang X, Tong L-J, Ding J, Duan W-H, Meng L-H (2014) DW09849, a selective phosphatidylinositol 3-kinase (PI3K) inhibitor, prevents pi3k signaling and preferentially inhibits proliferation of cells containing the oncogenic mutation p110a (H1047R). J Pharm Exp Ther 348:432-441

28. Hidalgo IJ, Raub TJ, Borchardt RT (1989) Characterization of the human colon carcinoma cell line (Caco-2) as a model system for intestinal epithelial permeability. Gastroenterol 96:736-749

29. Sambuy Y, De Angelis I, Ranaldi G, Scarino M, Stammati A, Zucco F (2005) The Caco-2 cell line as a model of the intestinal barrier: influence of cell and culture-related factors on Caco-2 cell functional characteristics. Cell Biol Toxicol 21:1-26

30. Leone V, Di Palma A, Ricchi P, Acquaviva F, Giannouli M, Di Prisco AM, Iuliano F, Acquaviva AM (2007) PGE2 inhibits apoptosis in human adenocarcinoma Caco-2 cell line through Ras-PI3K association and CAMPdependent kinase A activation. Am J Physiol Gastrointest Liver Physiol 293:G673-G681

31. Lee CM, Fuhrman CB, Planelles V, Peltier MR, Gaffney DK, Soisson AP, Dodson MK, Tolley HD, Green CL, Zempolich KA (2006) Phosphatidylinositol 3-kinase inhibition by LY294002 radiosensitizes human cervical cancer cell lines. Clin Cancer Res 12:250-256

32. Sarbassov DD, Guertin DA, Ali SM, Sabatini DM (2005) Phosphorylation and regulation of Akt/PKB by the rictor-mTOR complex. Science 307:1098-1101

33. Lee S, Choi E-J, Jin C, Kim D-H (2005) Activation of PI3K/Akt pathway by PTEN reduction and PIK3CA mRNA amplification contributes to cisplatin resistance in an ovarian cancer cell line. Gyneco Oncol 97:26-34

34. Sabbah DA, Simms NA, Brattain MG, Vennerstrom JL, Zhong H (2012) Biological evaluation and docking studies of recently identified inhibitors of phosphoinositide-3-kinases. Bioorg Med Chem Lett 22:876-880

35. Sabbah DA, Simms NA, Wang W, Dong Y, Ezell EL, Brattain MG, Vennerstrom JL, Zhong HA (2012) N-Phenyl-4-hydroxy-2-quinolone-3-carboxamides as selective inhibitors of mutant H1047R phosphoinositide3-kinase (PI3Ka). Bioorg Med Chem 20:7175-7183

36. Friesner RA, Banks JL, Murphy RB, Halgren TA, Klicic JJ, Mainz DT, Repasky MP, Knoll EH, Shelley M, Perry JK, Shaw DE, Francis P, Shenkin PS (2004) Glide: a new approach for rapid, accurate docking and scoring. 1. Method and assessment of docking accuracy. J Med Chem 47:1739-1749

37. Friesner RA, Murphy RB, Repasky MP, Frye LL, Greenwood JR, Halgren TA, Sanschagrin PC, Mainz DT (2006) Extra precision glide: docking and scoring incorporating a model of hydrophobic enclosure for protein-ligand complexes. J Med Chem 49:6177-6196

38. Sabbah DA, Vennerstrom JL, Zhong H (2010) Docking studies on isoformspecific inhibition of phosphoinositide-3-kinases. J Chem Inf Model 50:1887-1898

39. Sweidan K, Sabbah DA, Bardaweel S, Dush KA, Sheikha GA, Mubarak MS (2016) Computer-aided design, synthesis, and biological evaluation of new indole-2-carboxamide derivatives as PI3Ka/EGFR inhibitors. Bioorg Med Chem Lett 26(11):2685-2690 
40. Sabbah DA, Vennerstrom JL, Zhong HA (2012) Binding selectivity studies of phosphoinositide 3-kinases using free energy calculations. J Chem Inf Model 52:3213-3224

41. Sabbah DA, Saada M, Khalaf RA, Bardaweel S, Sweidan K, Al-Qirim T, Al-Zughier A, Halim HA, Sheikha GA (2015) Molecular modeling based approach, synthesis, and cytotoxic activity of novel benzoin derivatives targeting phosphoinostide 3-kinase (PI3Ka). Bioorg Med Chem Lett 25:3120-3124

42. Sweidan K, Sabbah DA, Engelmann J, Halim HA, Sheikha GA (2015) Computational docking studies of novel heterocyclic carboxamides as potential PI3Ka inhibitors. Lett Drug Des Discov 12:856-863

43. The Molecular operating (2016) Environment chemical computing group. Inc Montreal, Quebec Canada

44. Mandelker D, Gabelli SB, Schmidt-Kittler O, Zhu J, Cheong I, Huang C-H, Kinzler KW, Vogelstein B, Amze LM (2009) A frequent kinase domain mutation that changes the interaction between PI3K alpha and the membrane. Proc Natl Acad Sci USA 106:16996-17001

45. Cho AE, Guallar V, Berne BJ, Friesner R (2005) Importance of accurate charges in molecular docking: quantum mechanical/molecular mechanical (QM/MM) approach. J Comput Chem 26:915-931
46. Protein Preparation Wizard (2012) Maestro, macromodel, phase, induced fit, jaguar, and glide. Schrödinger, LLC, Portland

47. Wu G, Xing M, Mambo E, Huang X, Liu J, Guo Z, Chatterjee A, Goldenberg D, Gollin SM, Sukumar S, Trink B, Sidransky D (2005) Somatic mutation and gain of copy number of PIK3CA in human breast cancer. Breast Cancer Res 7:R609-R616

48. Beaver JA, Gustin JP, Yi KH, Rajpurohit A, Thomas M, Gilbert SF, Rose DM, Park BH, Lauring J (2013) PIK3CA and AKT1 mutations have distinct effects on sensitivity to targeted pathway inhibitors in an isogenic luminal breast cancer model system. Clin Cancer Res 19:5413-5422

49. She Q-B, Chandarlapaty S, Ye Q, Lobo J, Haskell KM, Leander KR, DeFeoJones D, Huber HE, Rosen N (2008) Breast tumor cells with PI3K mutation or HER2 amplification are selectively addicted to Akt signaling. PLOS ONE 3:e3065-e3068

50. Weigelt B, Warne PH, Downward J (2011) PIK3CA mutation, but not PTEN loss of function, determines the sensitivity of breast cancer cells to mTOR inhibitory drugs. Oncogene 30:3222-3233

51. Zardavas D, Phillips WA, Loi S (2014) PIK3CA mutations in breast cancer: reconciling findings from preclinical and clinical data. Breast Cancer Res 16:201-208
Ready to submit your research? Choose BMC and benefit from:

- fast, convenient online submission

- thorough peer review by experienced researchers in your field

- rapid publication on acceptance

- support for research data, including large and complex data types

- gold Open Access which fosters wider collaboration and increased citations

- maximum visibility for your research: over 100M website views per year

At BMC, research is always in progress.

Learn more biomedcentral.com/submissions 